\title{
Medical gallery of Mikael Häggström 2014
}

Mikael Häggström

\section{Abstract}

This is a gallery of images contributed to Wikimedia projects by Mikael Häggström by 2014. Many of these images may be too small to conveniently view the content. Larger versions are available online.

\section{Contents}

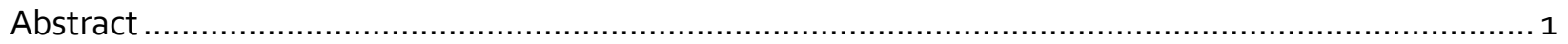

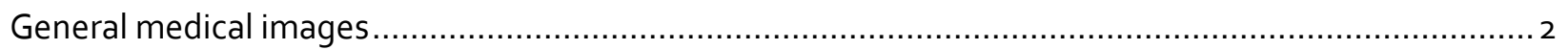

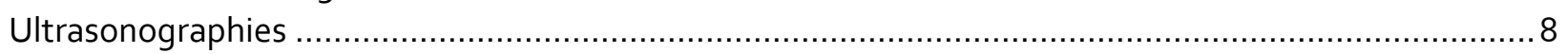

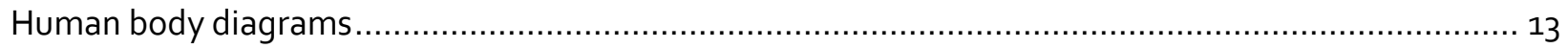

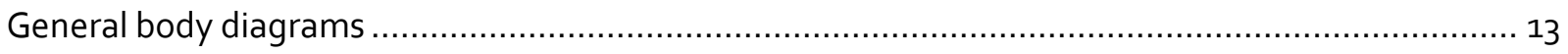

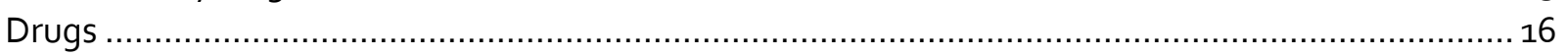

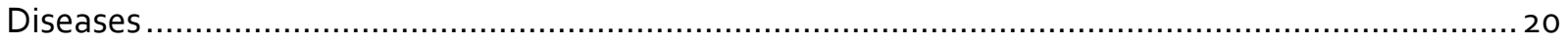

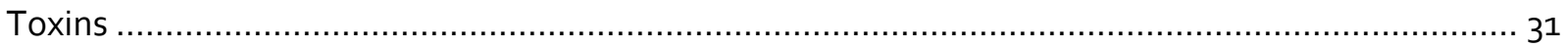

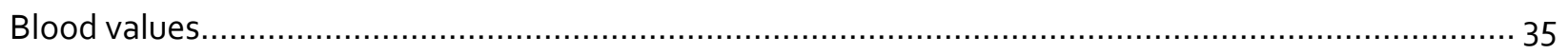

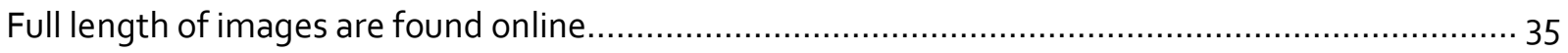

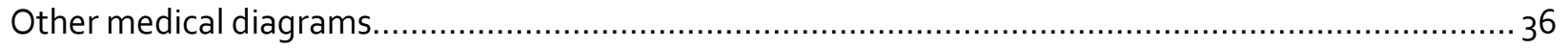

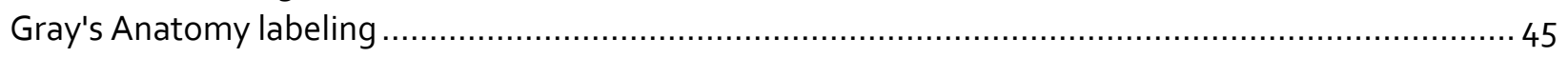

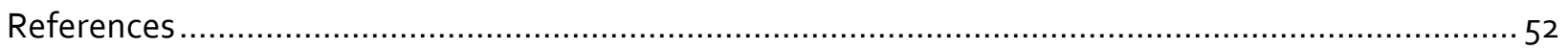

Diabetes, rheumatoid arthritis, Parkinson's, Alzheimer's disease, osteoarthritis ............................ 52

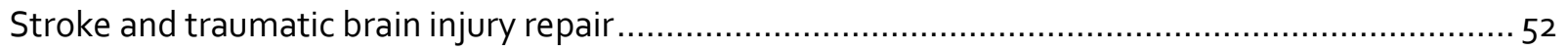

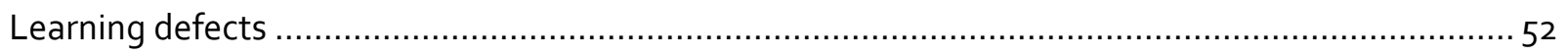

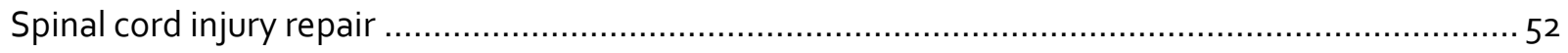

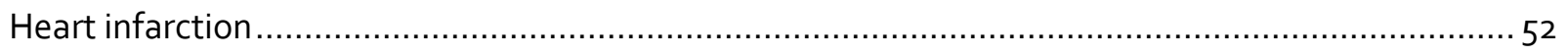

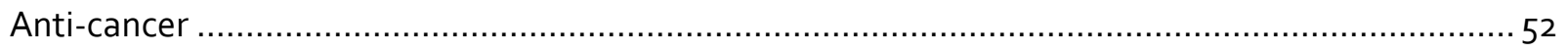

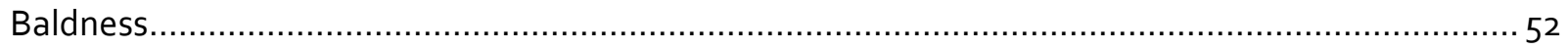

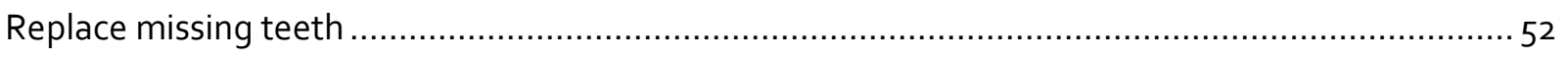

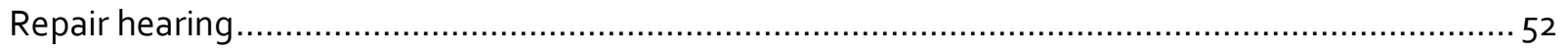

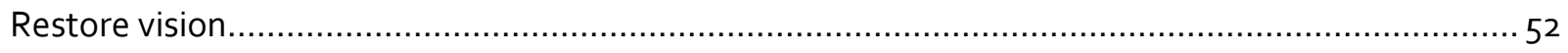

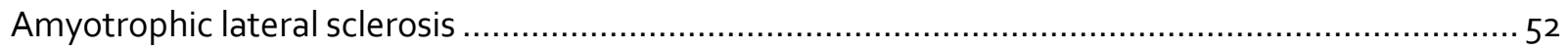

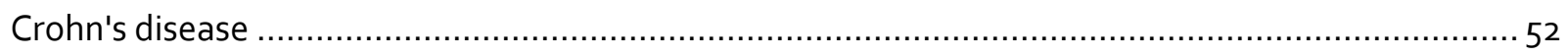

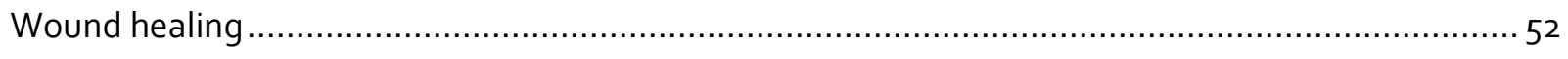

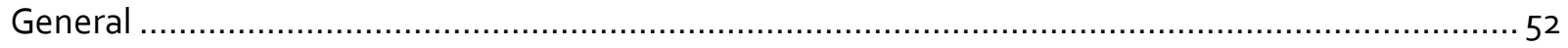




\section{General medical images}

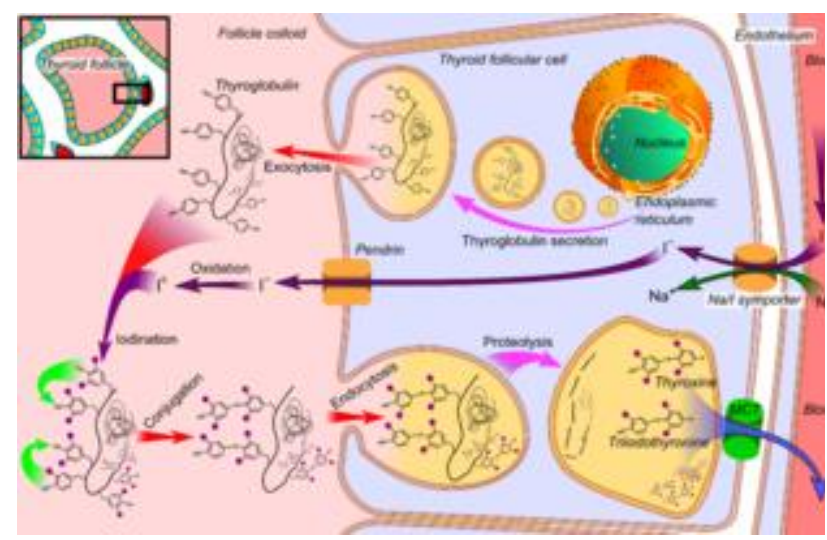

Thyroid hormone synthesis

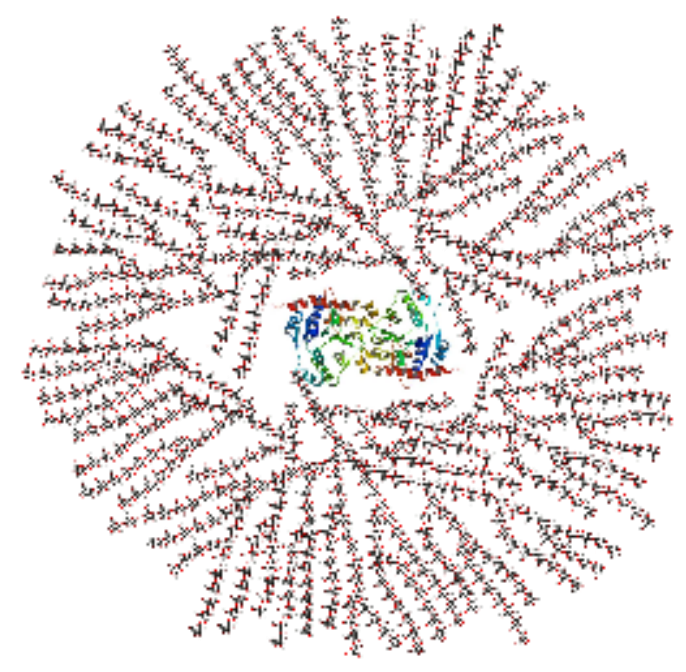

Glycogen structure
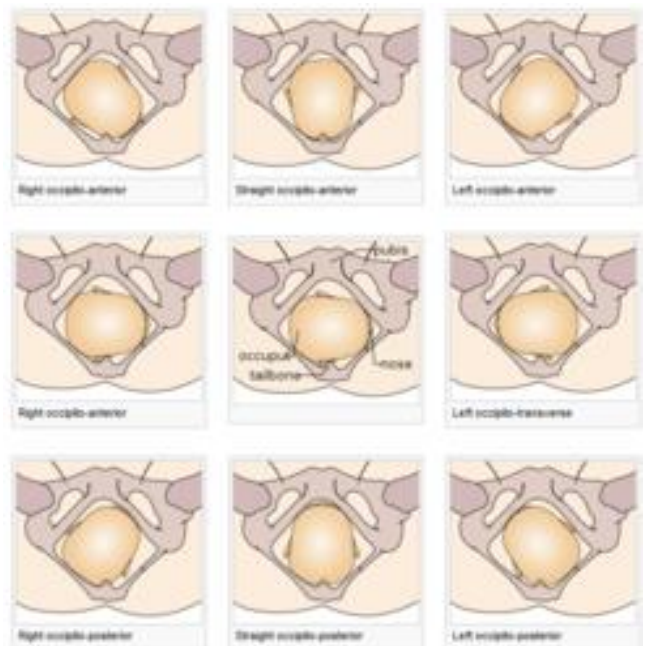

Cephalic presentations

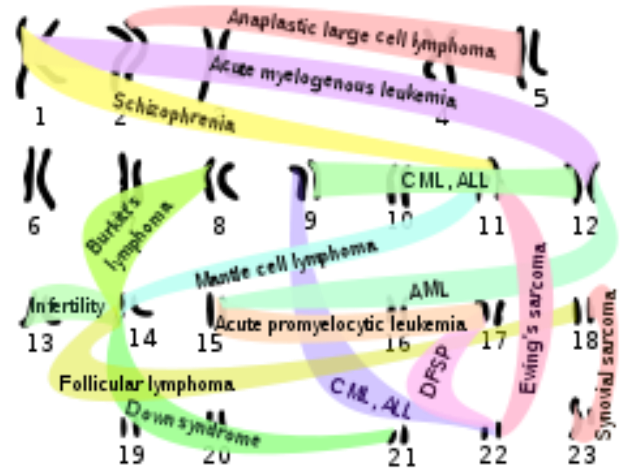

Chromosomal translocations

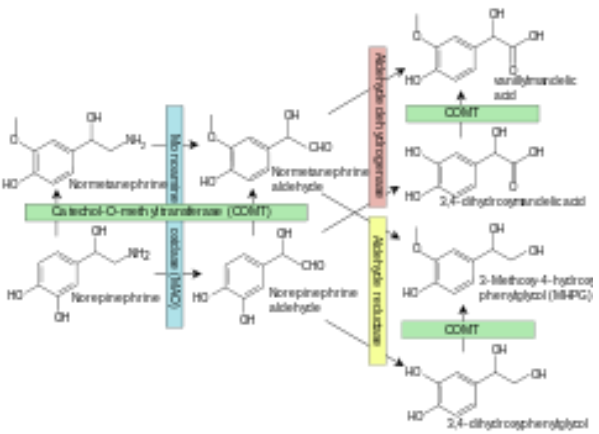

Noradrenaline breakdown 


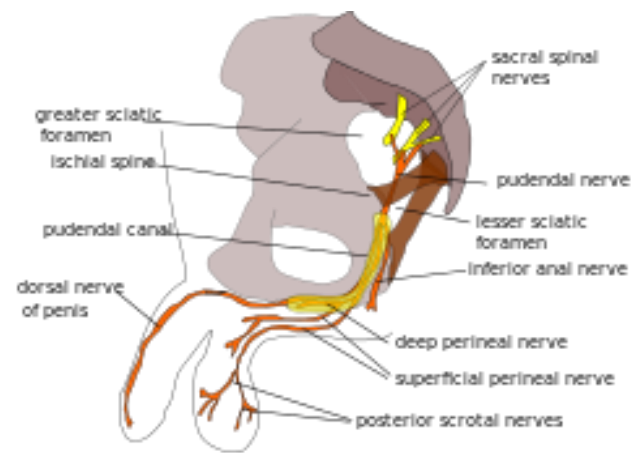

Pudendal nerve

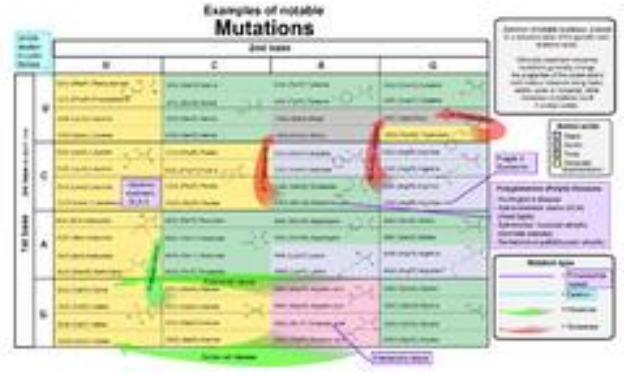

Notable mutations

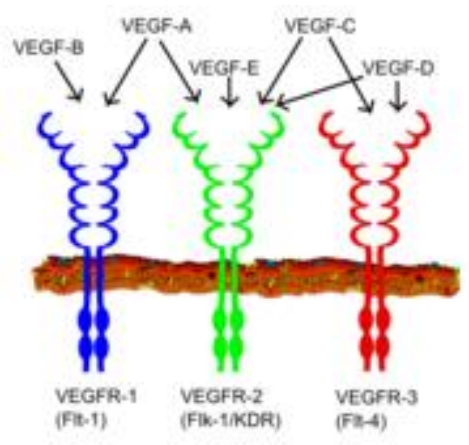

VEGF receptors 


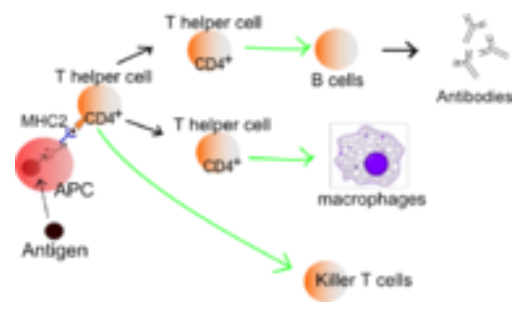

Lymphocyte activation (simple)

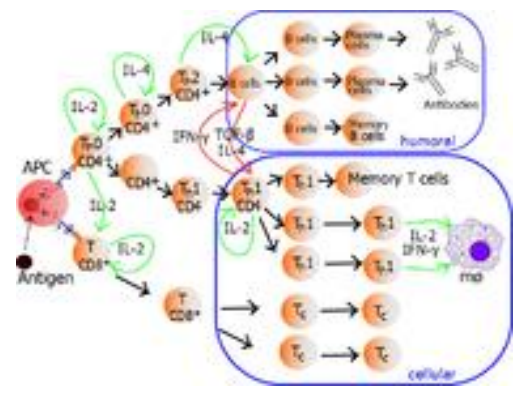

Lymphocyte activation (more detailed)

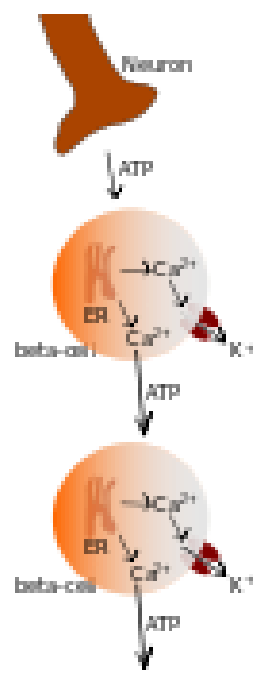

Insulin oscillations coordination

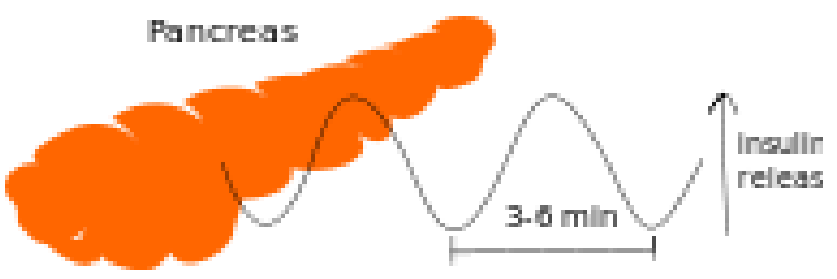

Pancreatic insulin oscillations
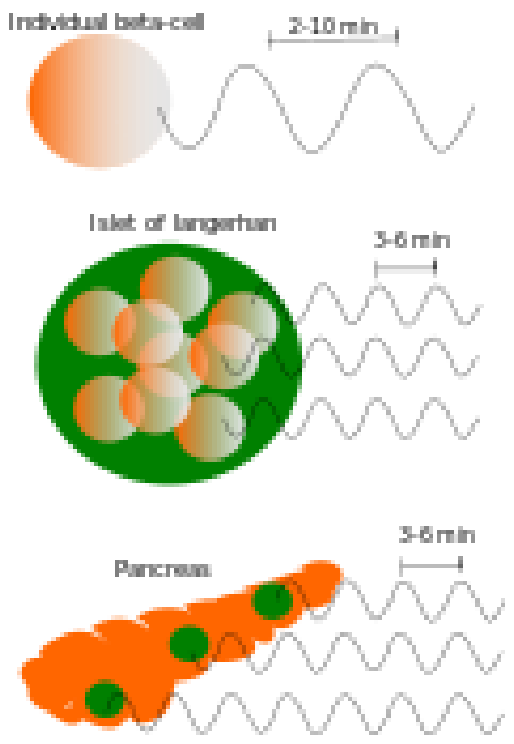

Cellular insulin oscillations

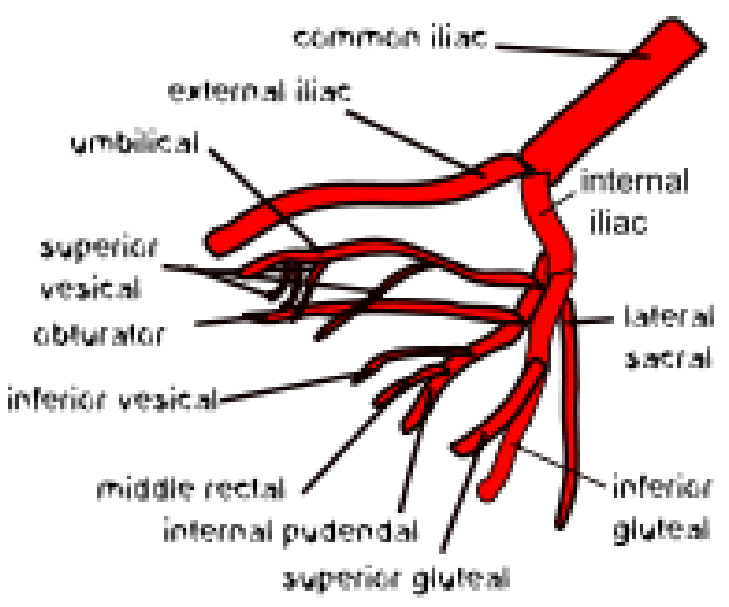

One variation of internal iliac artery branching (4 more versions not shown here) 


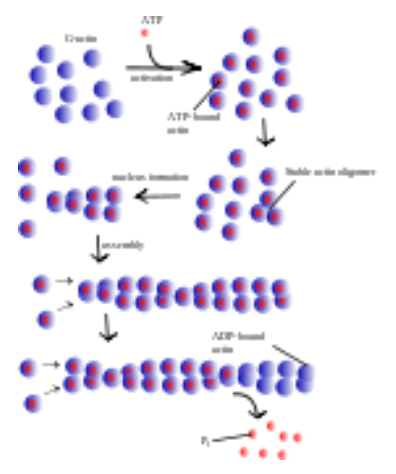

Thin filament formation

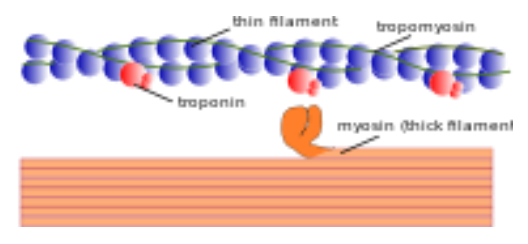

Myofilament

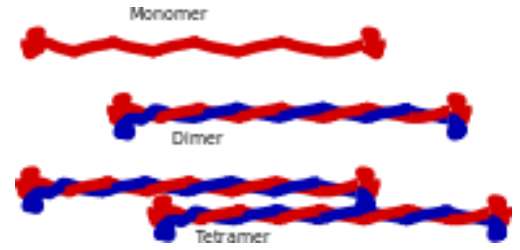

Intermediate filament

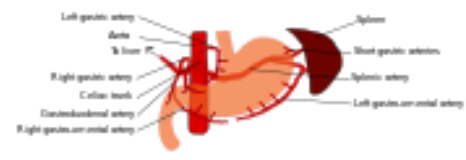

Blood supply of the stomach

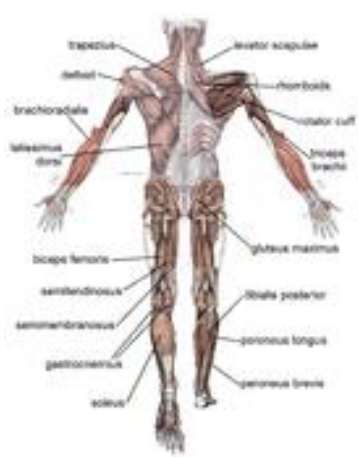

Posterior muscles

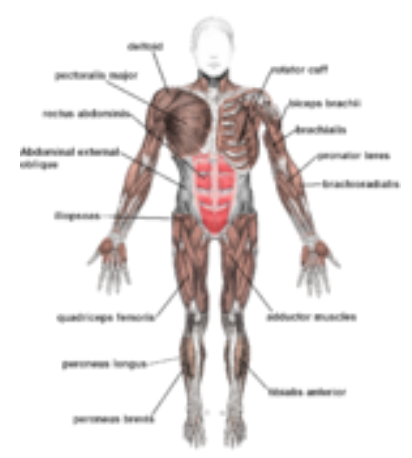

Anterior muscles

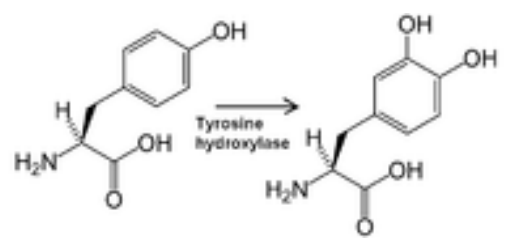

Tyrosine hydroxylase reaction 


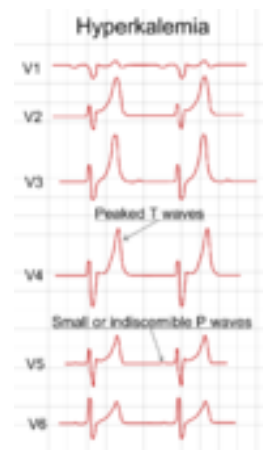

ECG in hyperkalemia

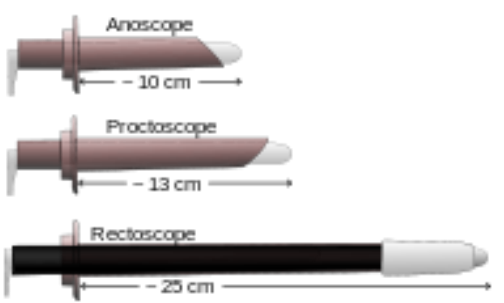

Anoscope, proctoscope andrectoscope

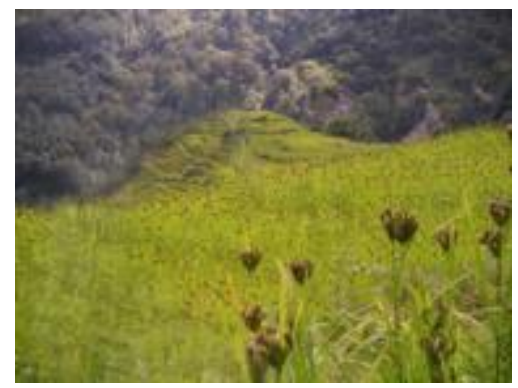

Scintillating scotoma

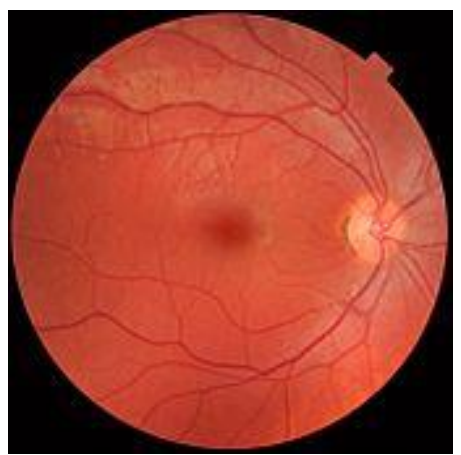

Fundus photograph of normal right eye

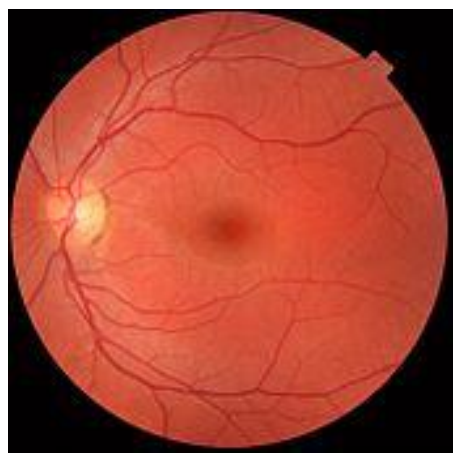

Fundus photograph of normal left eye

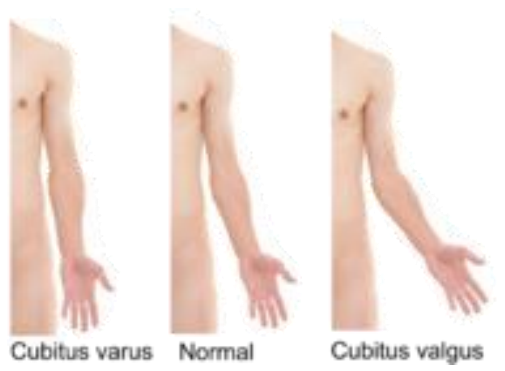

Cubitus varus and cubitus valgus 


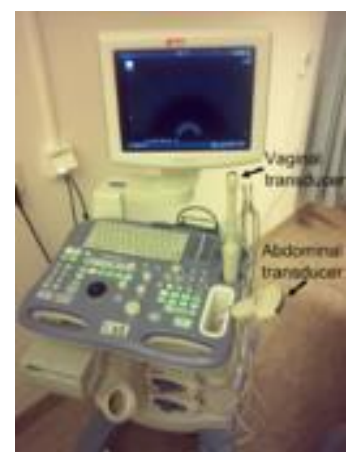

Transvaginal ultrasonographydevice

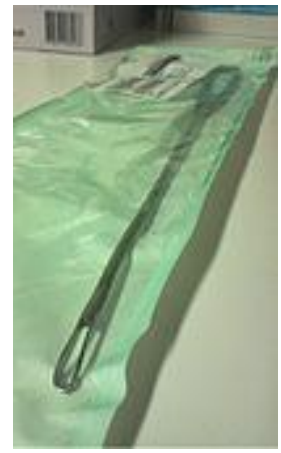

Curette

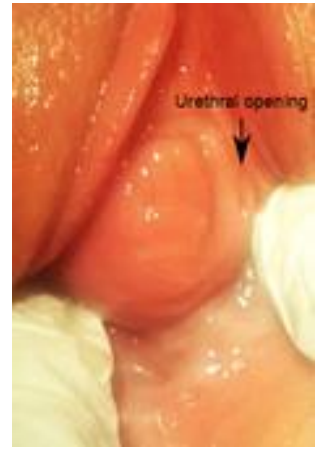

Skene's duct cyst

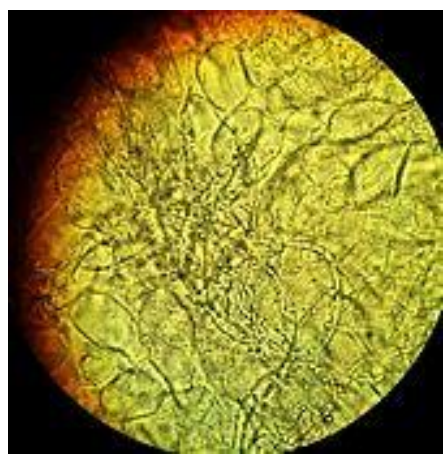

Vaginal wet mount of candidal vulvovaginitis

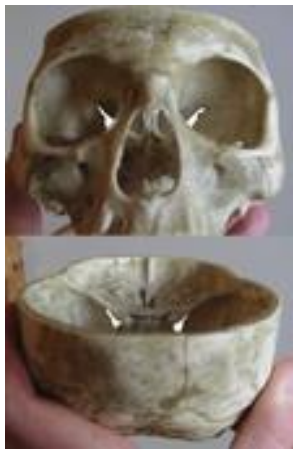

Superior orbital fissure

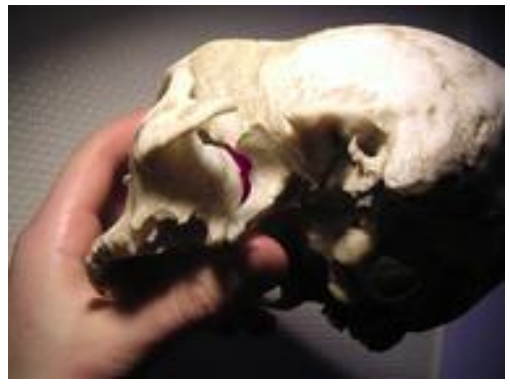

Entrance to pterygopalatine fossa 


\section{Ultrasonographies}

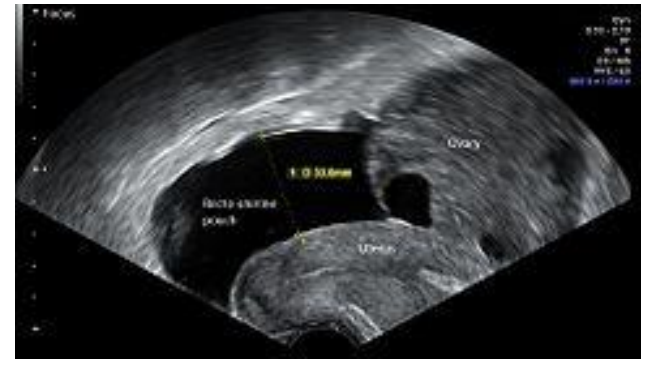

Ovarian hyperstimulation syndrome

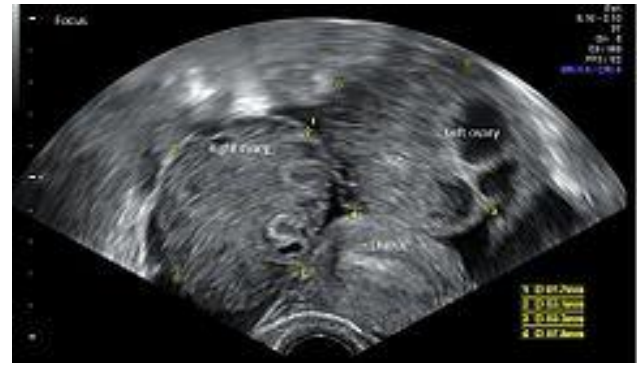

Ovarian hyperstimulation syndrome

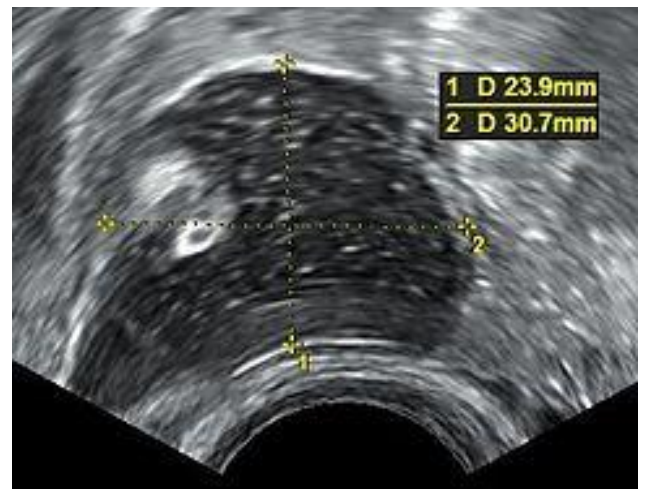

Dermoid cyst

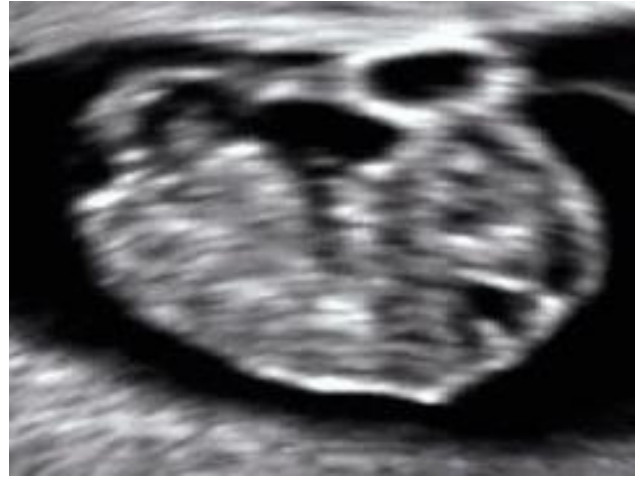

Movements at a gestational age of 9 weeks.

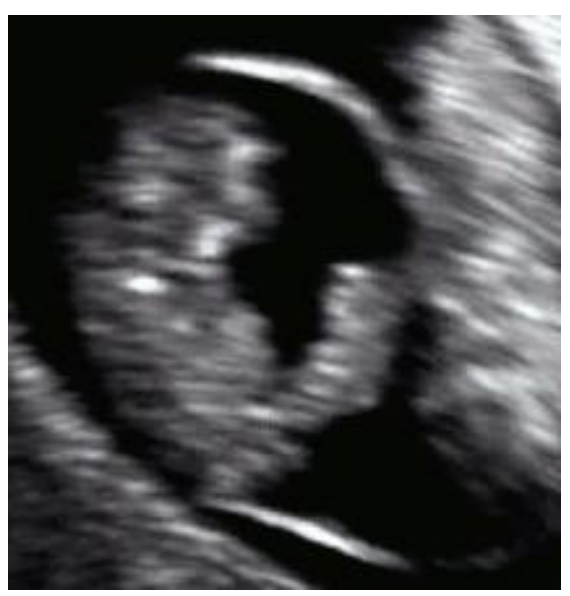

Umbilical cord 


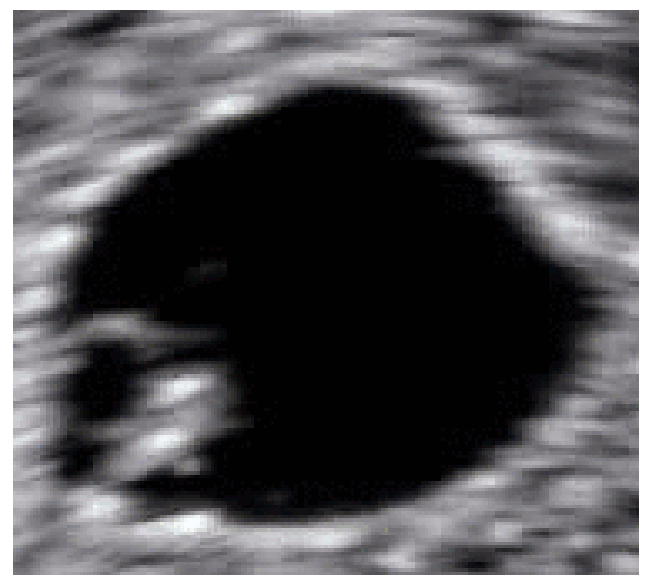

Heartbeat at 5 weeks and 5 days ofgestational age

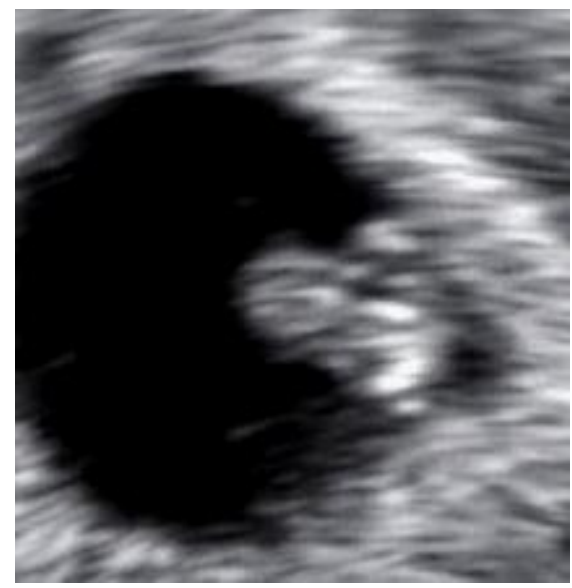

Heartbeat at 6 weeks 1 day

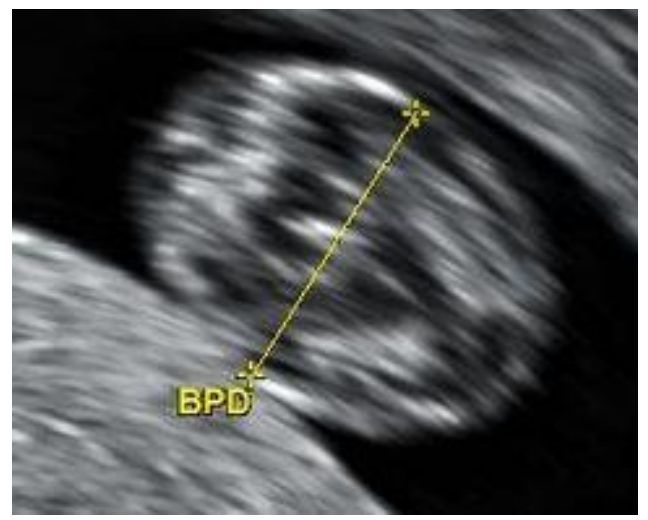

$\mathbf{9}$ of $\mathbf{5 3} \mid$ WikiJournal of Medicine
Biparietal diameter

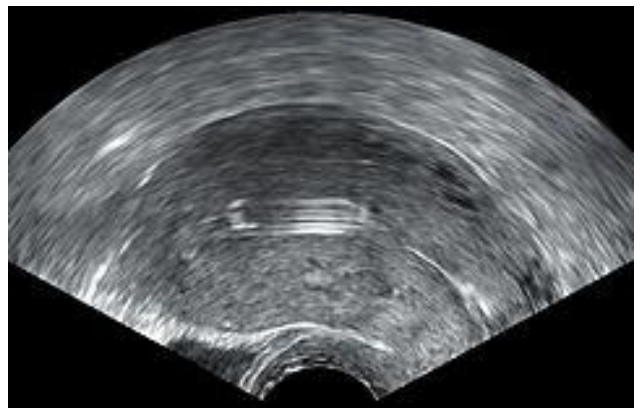

Intrauterine device

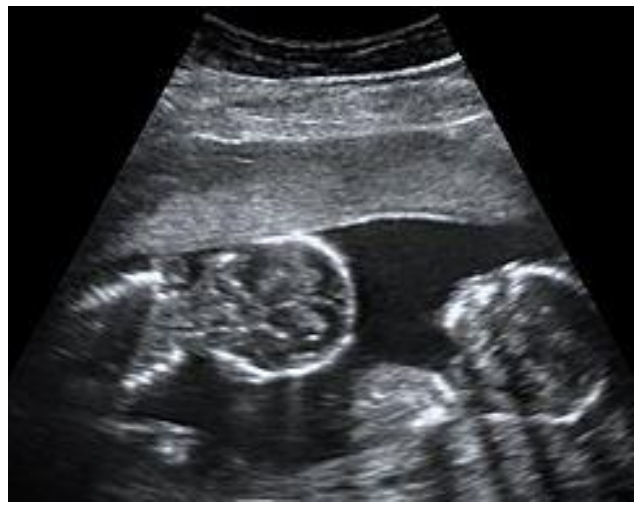

Monoamniotic twins

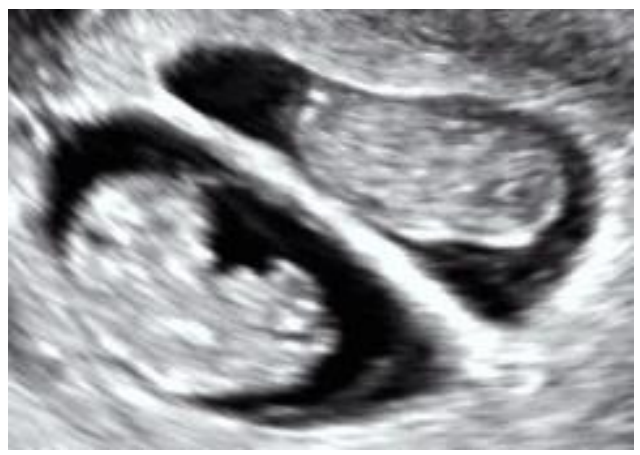

Dichorionic twins 


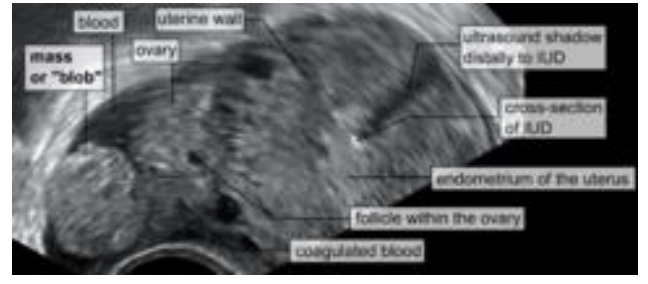

Ectopic pregnancy

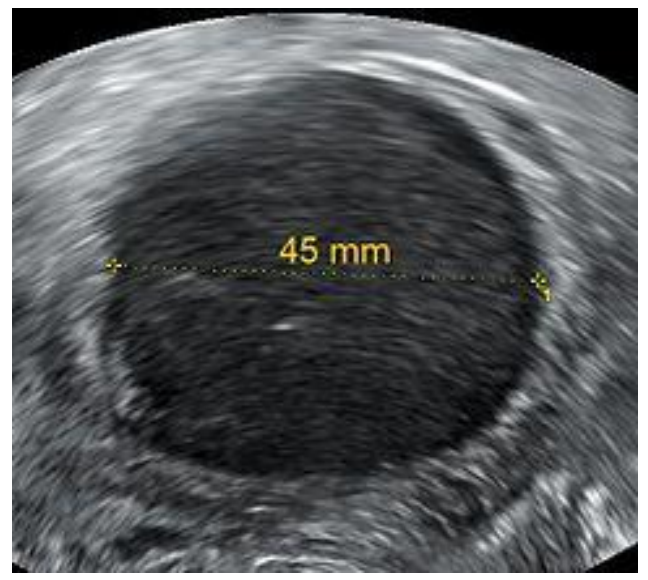

Hemorrhagic ovarian cyst

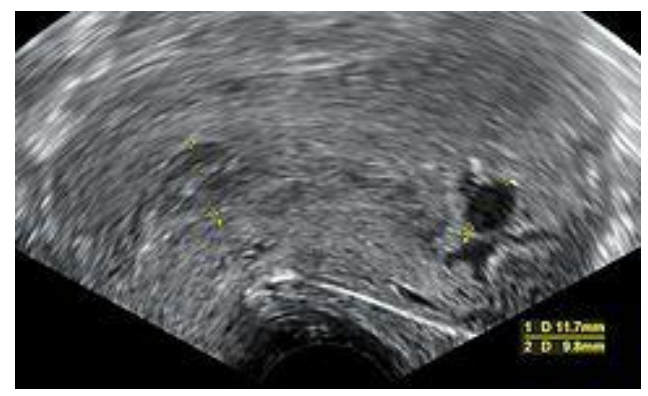

Incomplete miscarriage

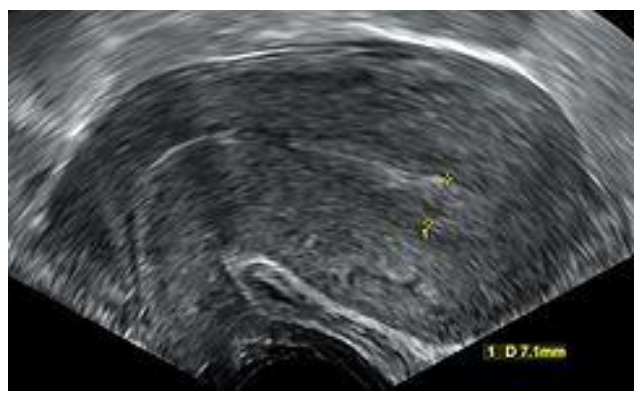

Complete miscarriage

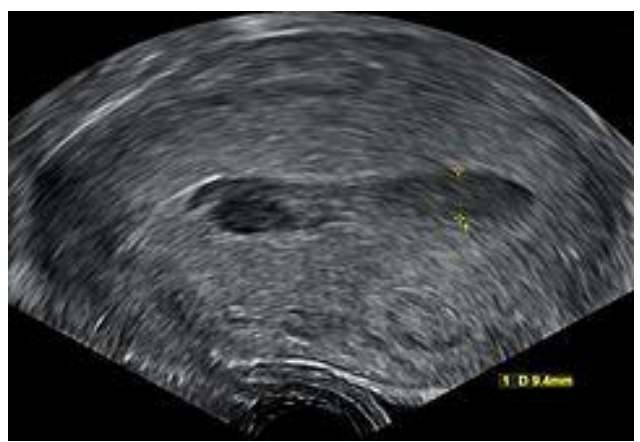

Hematometra

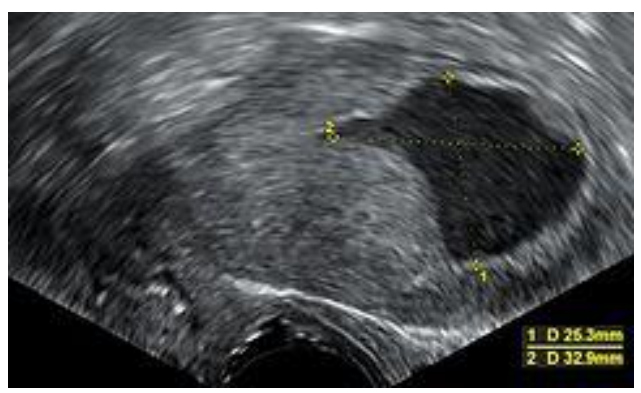

Postmenopausal endometrial fluid 


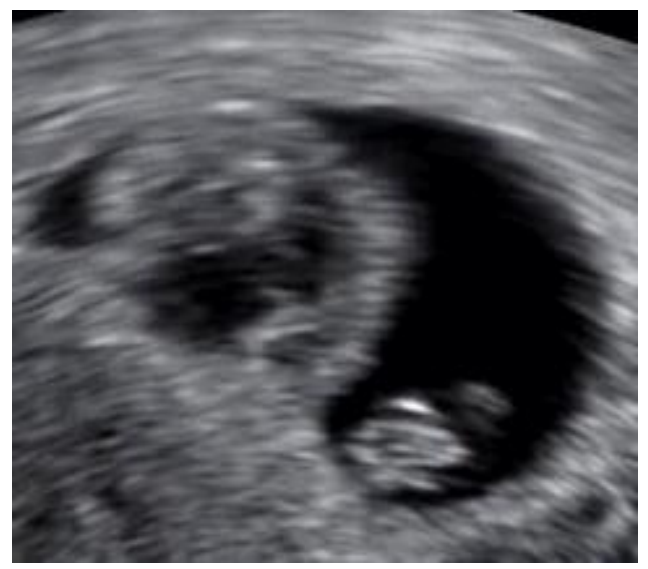

Abnormal mass and normal embryo

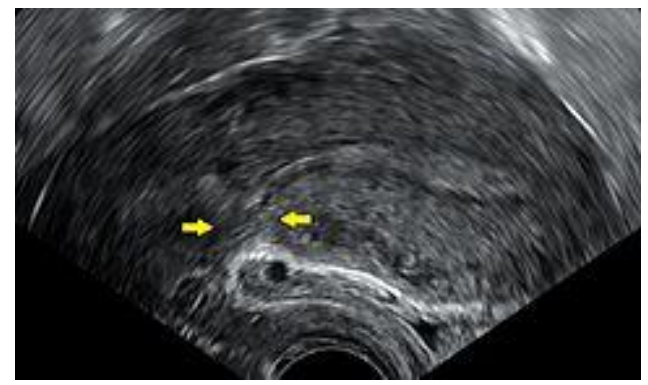

Uterus after Caesarean section
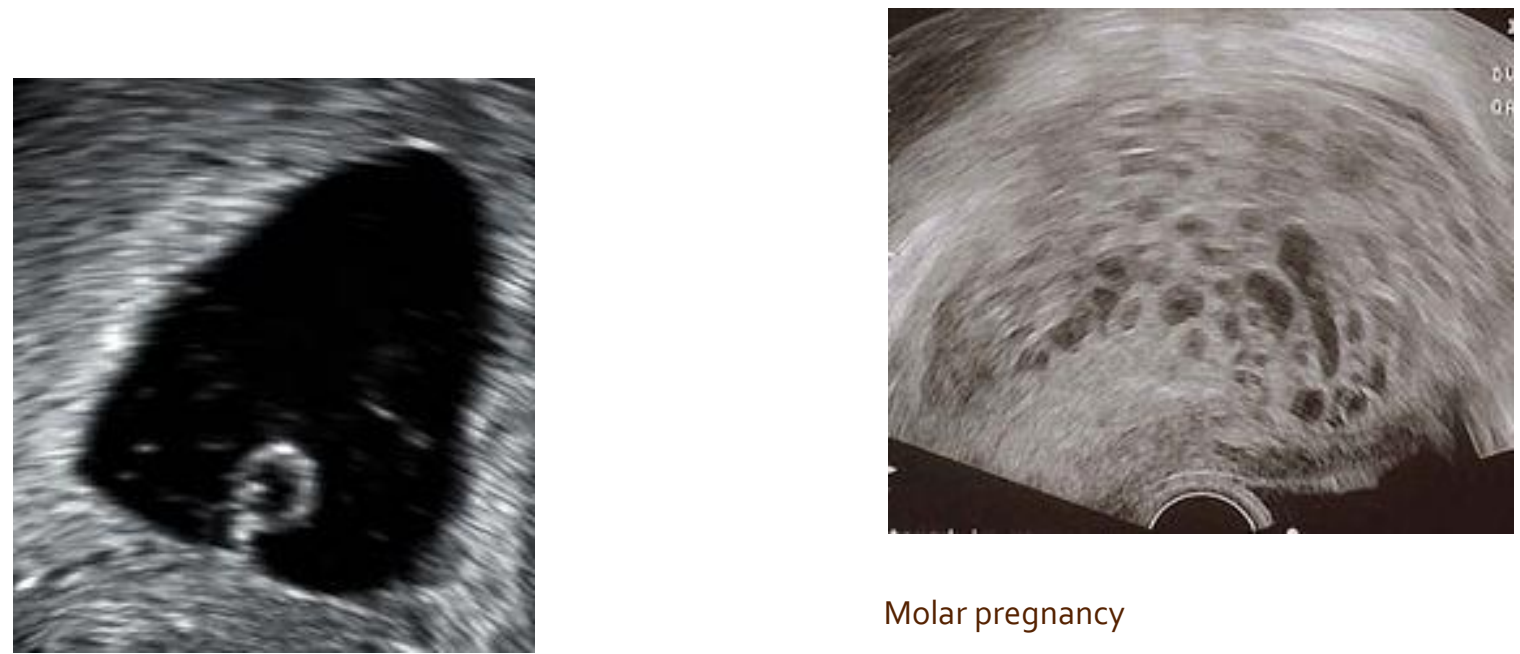

Molar pregnancy

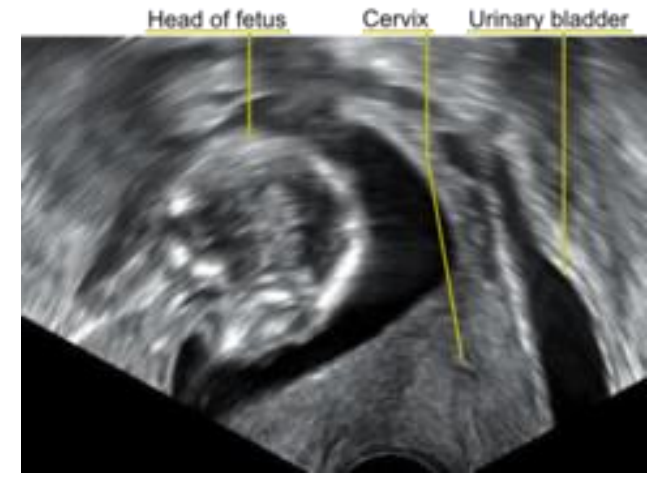

\section{Retroverted uterus in pregnancy}

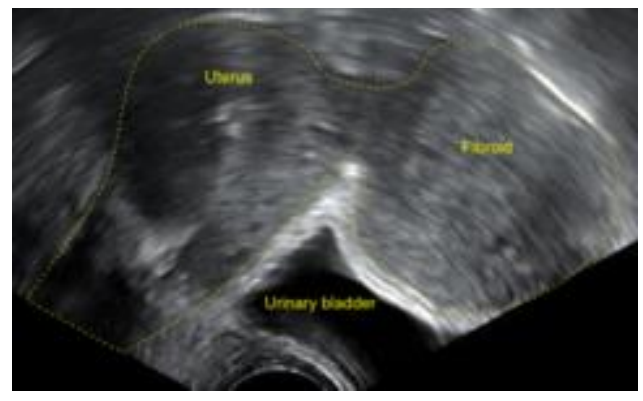

Subserosal uterine fibroid

Anembryonic gestation 


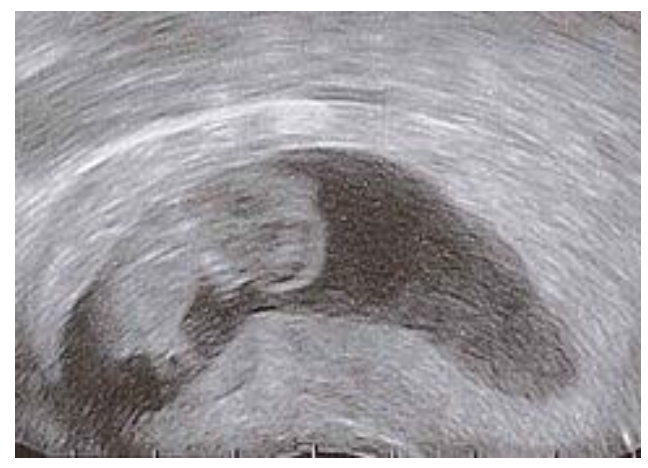

Almost completed medical abortion

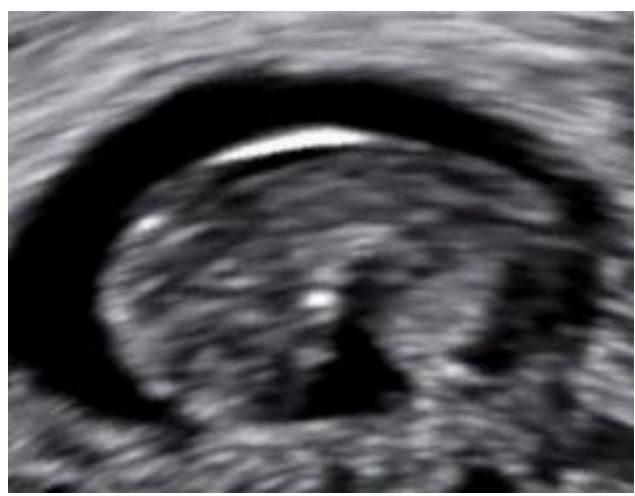

Delayed or missed miscarriage

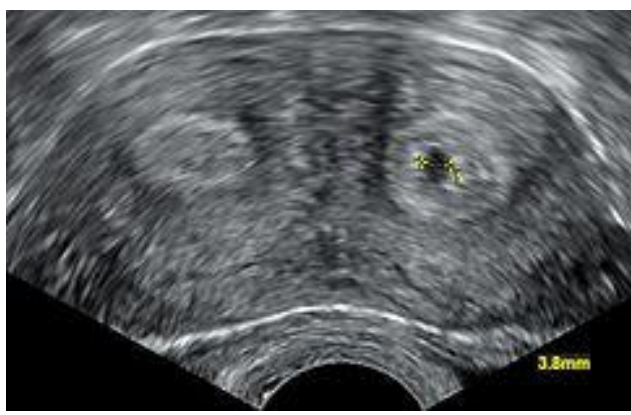

Bicornuate uterus with pregnancy 


\section{Human body diagrams}

The human body diagrams are a collection of images that are derived mainly from public domain pictures of organs, like a drag-and-drop doll. Their main purpose is to provide overviews, explaining medical conditions and other phenomena in a more convenient way.

\section{General body diagrams}

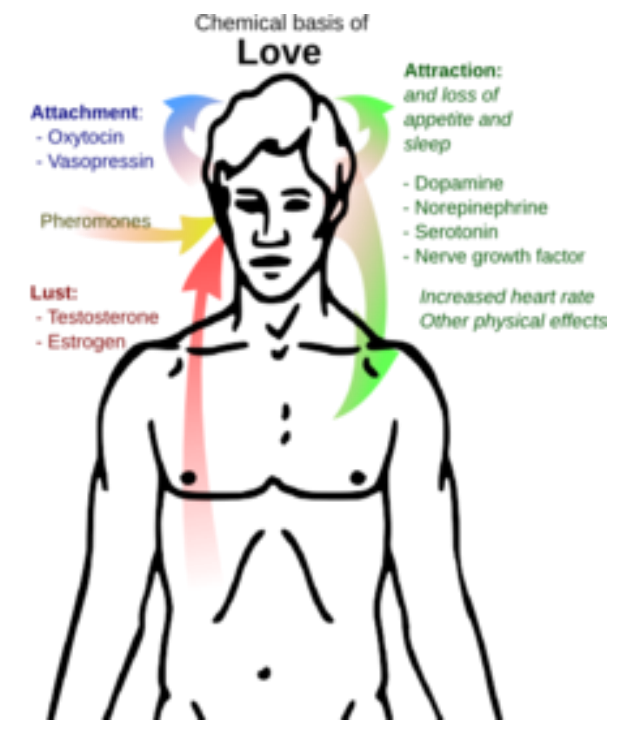

Simplistic overview of the chemical basis of love.

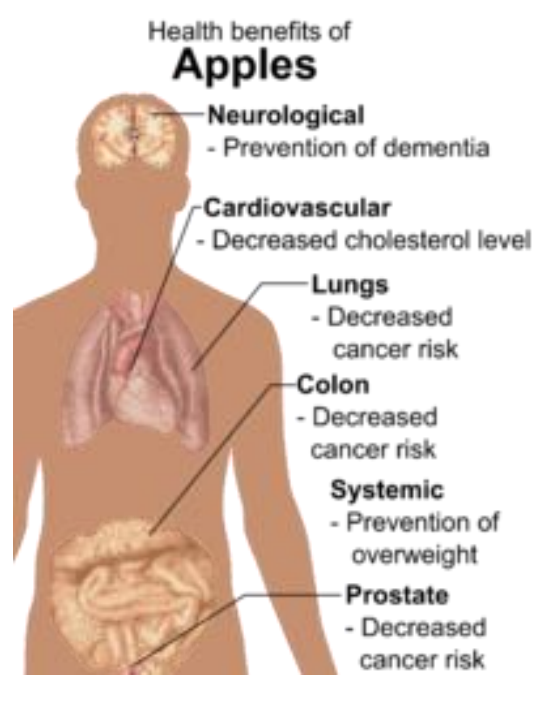

Potential health benefits of appleconsumption. ${ }^{[1][2][3][4]}$ 


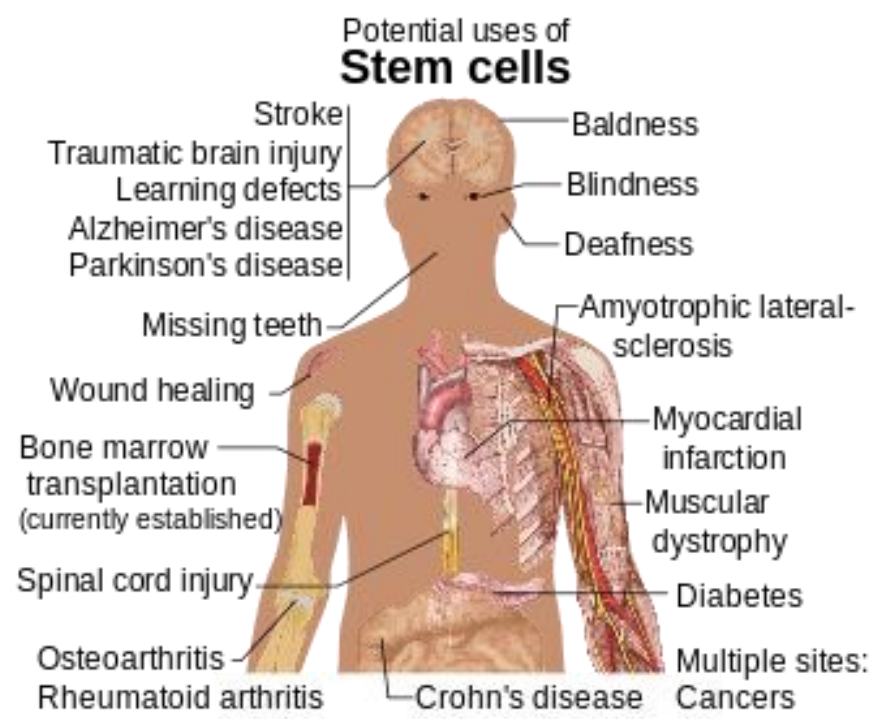

Diseases and conditions where stem cell treatment is promising or emerging. ${ }^{[5]}$ Bone marrow transplantation is, as of 2009, the only established use of stem cells.

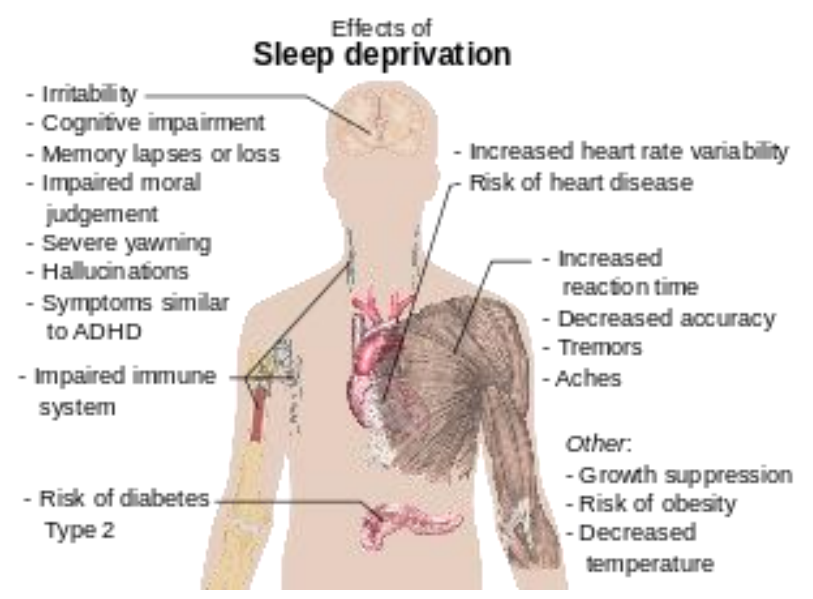

Main health effects of sleep deprivation. ${ }^{[6]}$. 


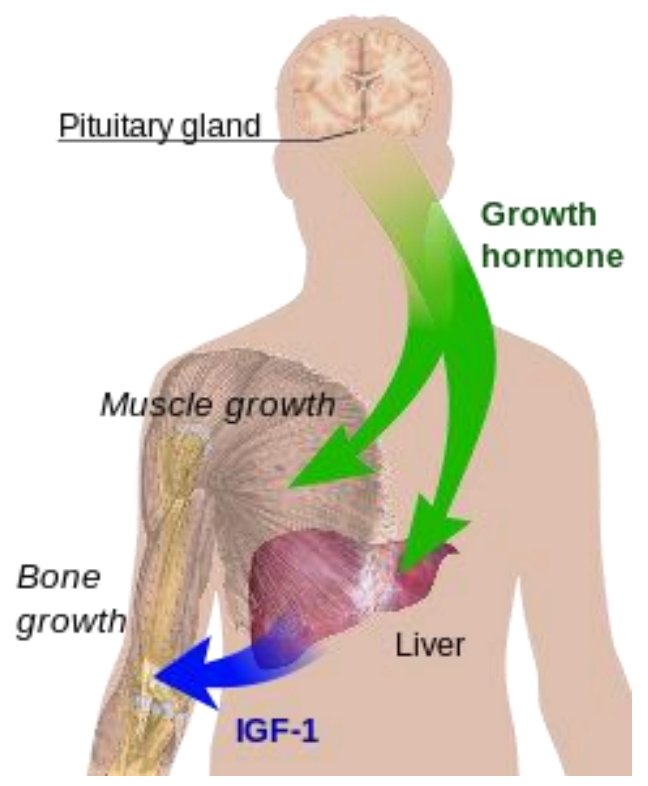

Main pathways in growth regulation by the endocrine system, mediated bygrowth hormone and insulin-like growth factor 1 (IGF-1).

\section{Glucose metabolism}

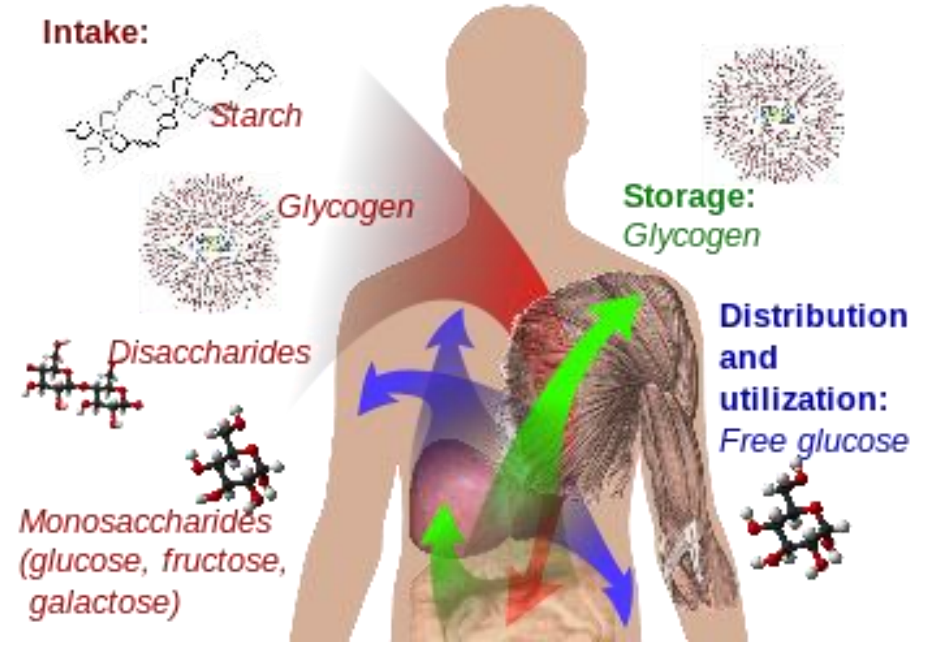

Glucose metabolism and various forms of it in the process.

-Glucose-containing compounds and isomeric forms are digested and taken up by the body in the intestines, includingstarch, glycogen, disaccharides and monosaccharides.

-Glucose is stored in mainly the liver and muscles as glycogen.

-It is distributed and utilized in tissues as free glucose. 


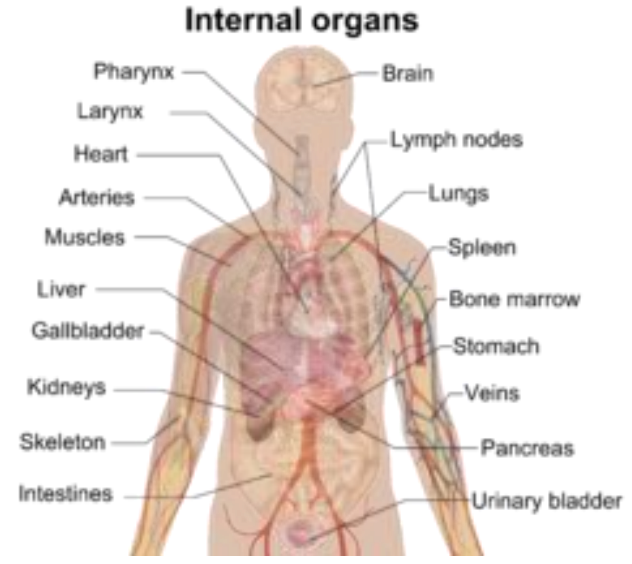

Internal organs.

\section{Drugs}

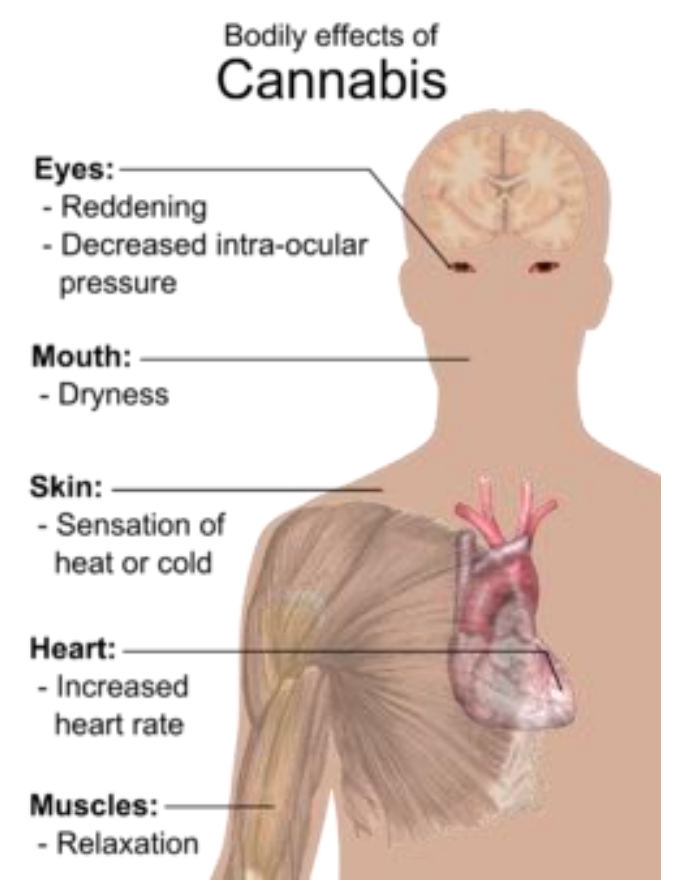

Main short-term somatic (bodily) effects of cannabis. 


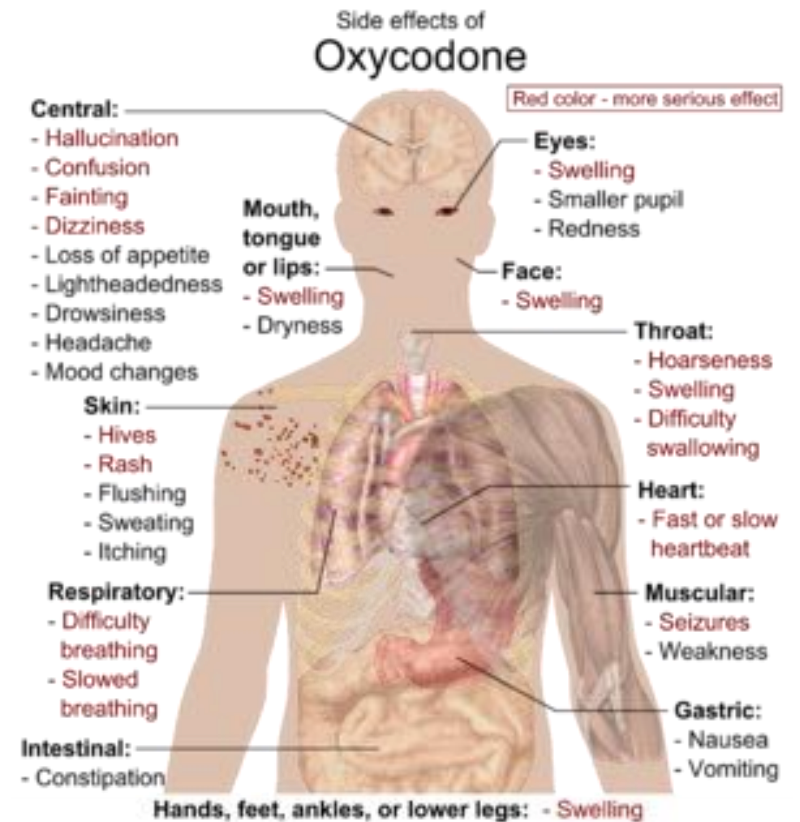

Main side effects of oxycodone. Red color denotes more serious effects, requiring immediate contact with health provider. $^{[7]}$

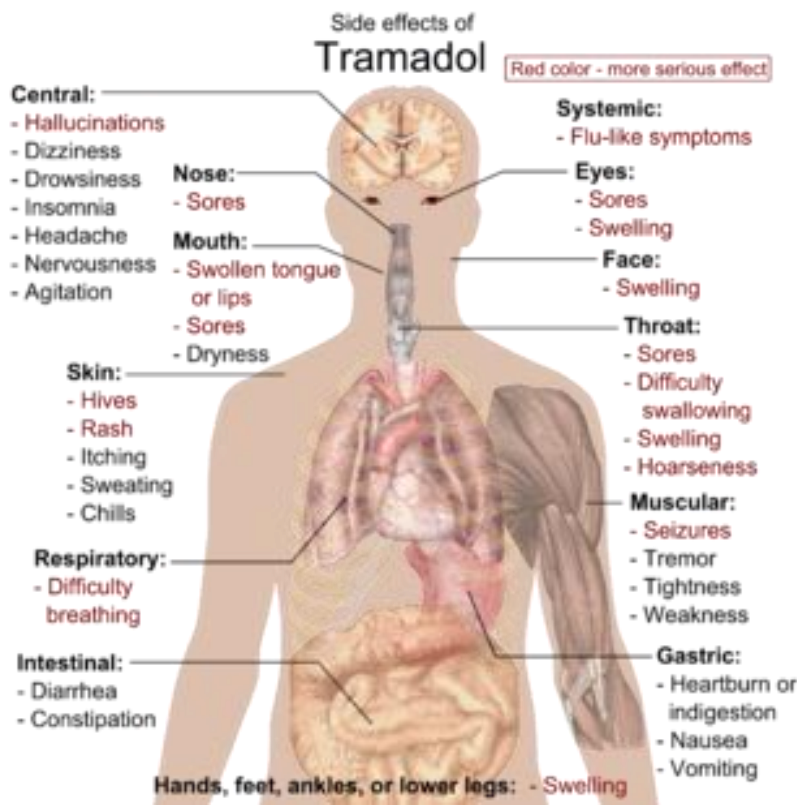

Main side effects of tramadol. Red color denotes more serious effects, requiring immediate contact with health provider. ${ }^{[10]}$ 


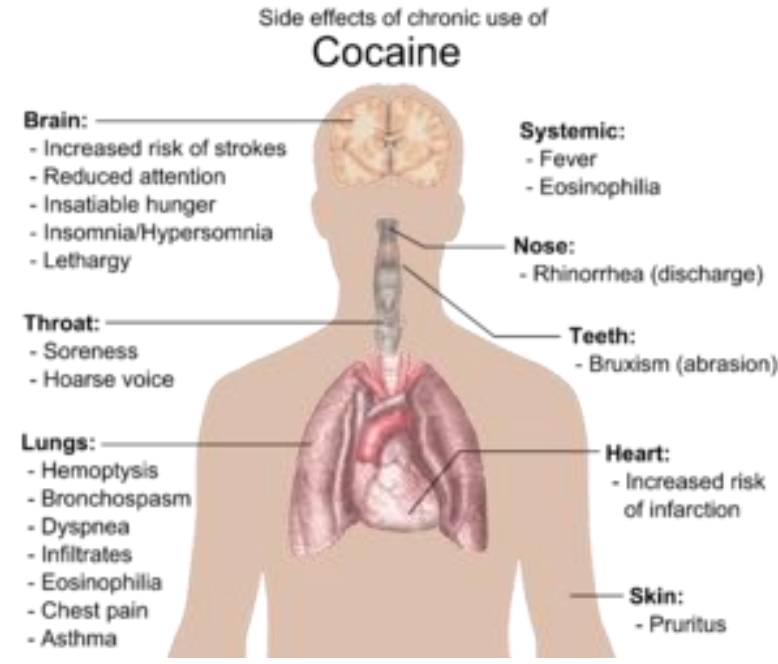

Main effects of chronic cocaine use.

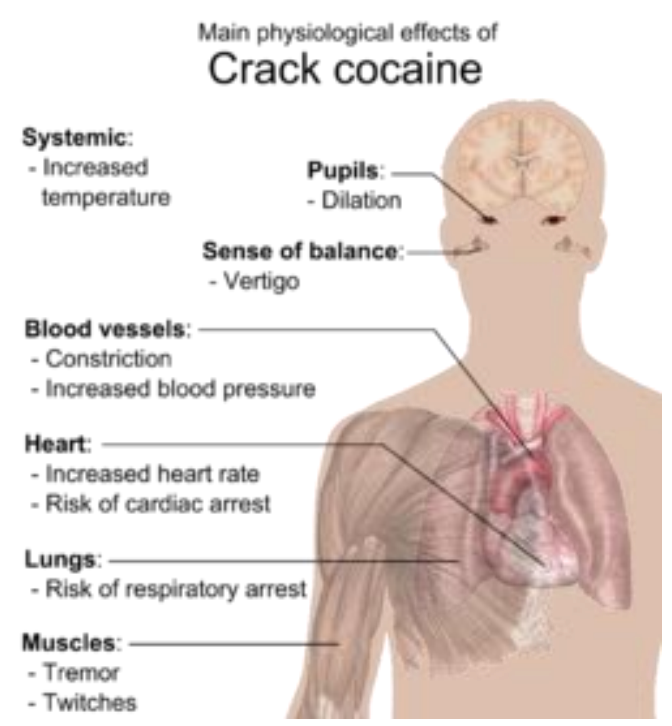

Main physiological effects of Crack cocaine. 


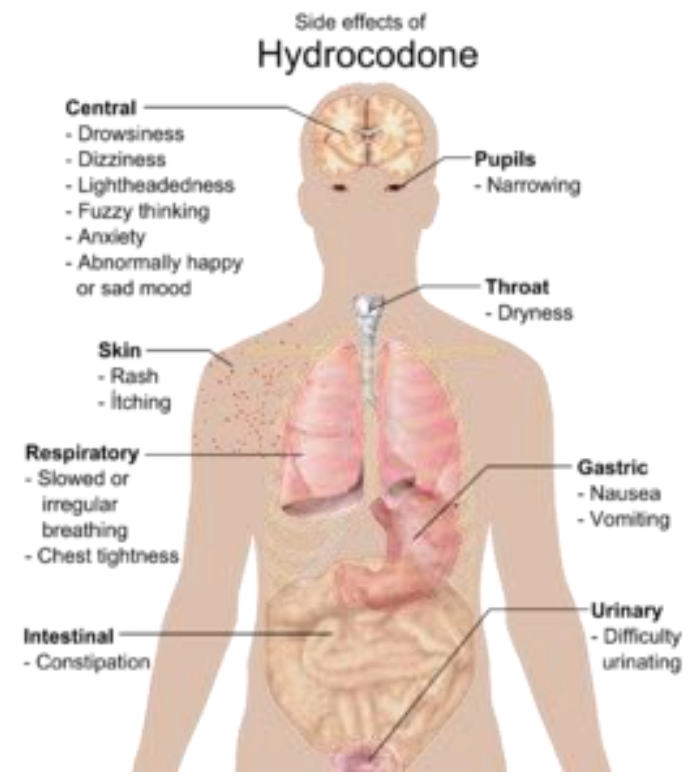

Main side effects of hydrocodone. ${ }^{[8]}$ The respiratory effects are most serious, requiring immediate contact with health provider. ${ }^{[8]}$

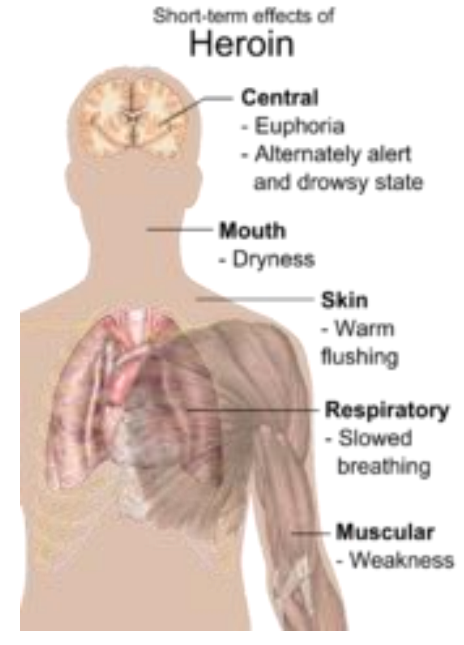

Main short-term effects of heroin usage. ${ }^{[9]}$

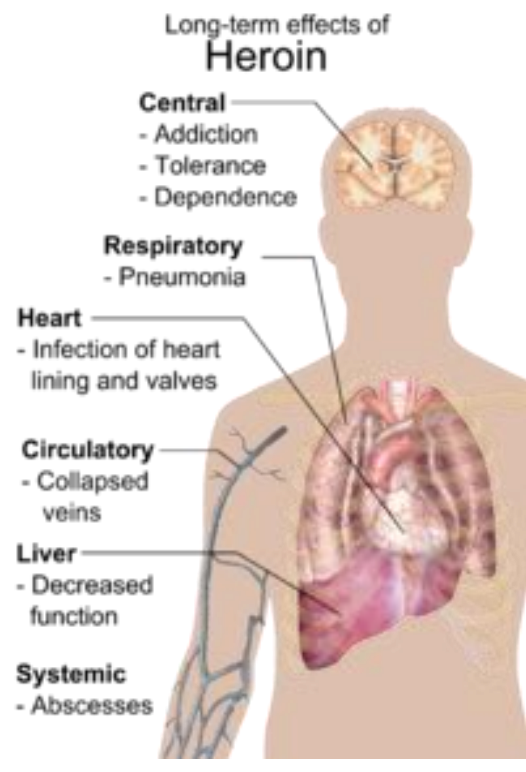

Main long-term effects of heroin usage. ${ }^{[9]}$ 


\section{Diseases}

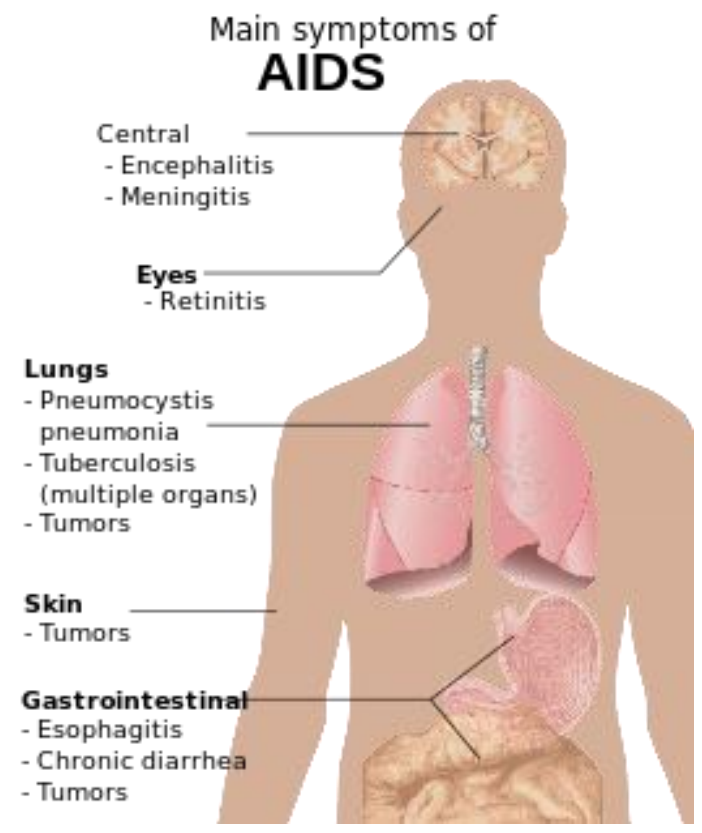

Main symptoms of AIDS.

\section{Main complic ations of persistent \\ High blood pressure}

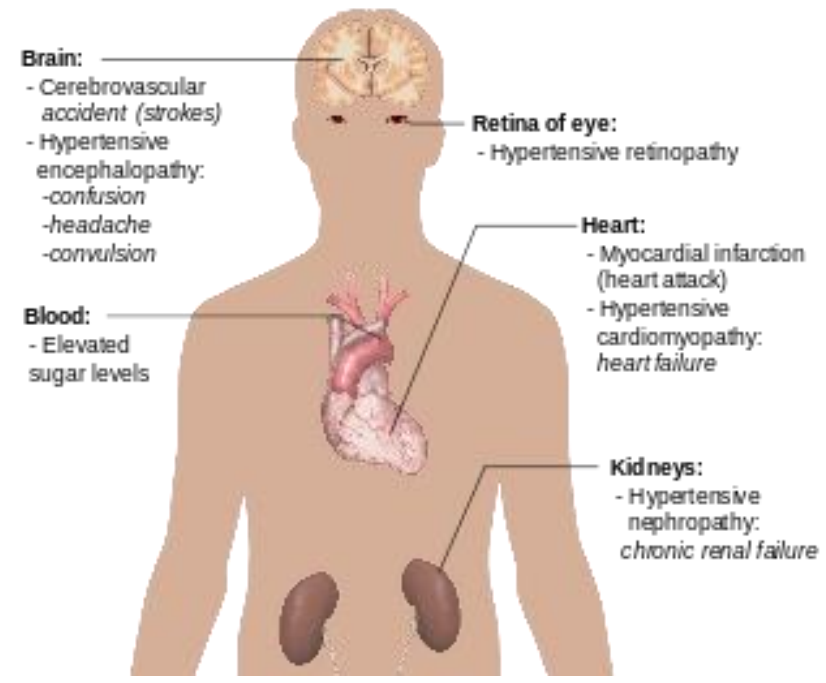

Overview, showing main complications of persistent high blood pressure. 


\section{Common sites and symptoms of Cancer metastasis}

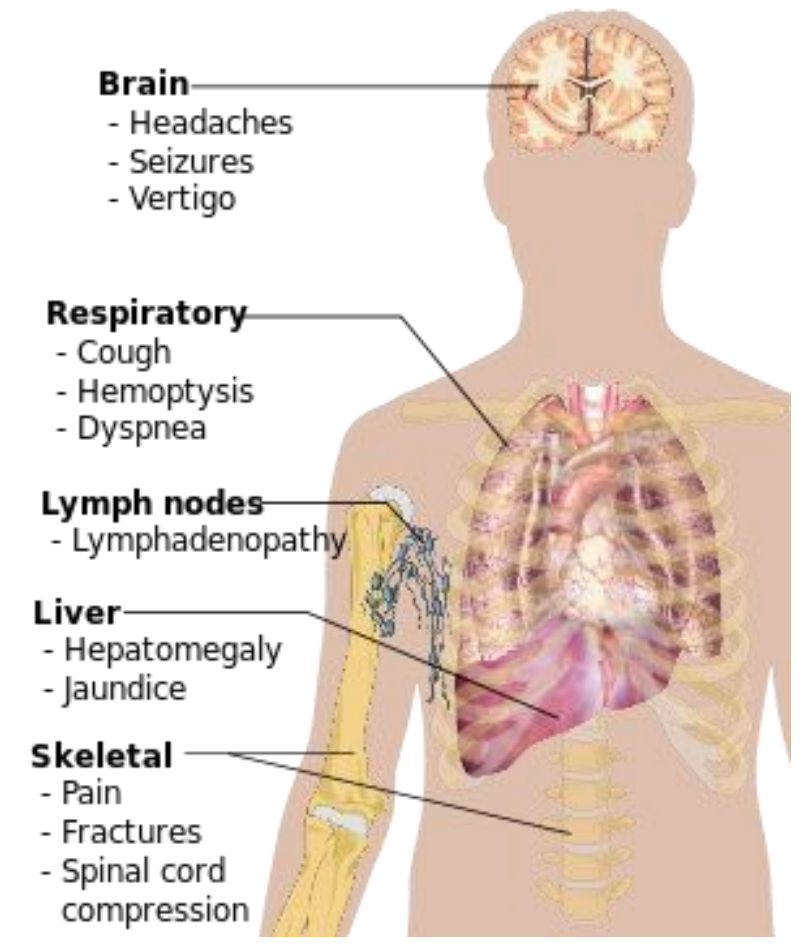

Symptoms of cancer metastasis depend location of the tumor.

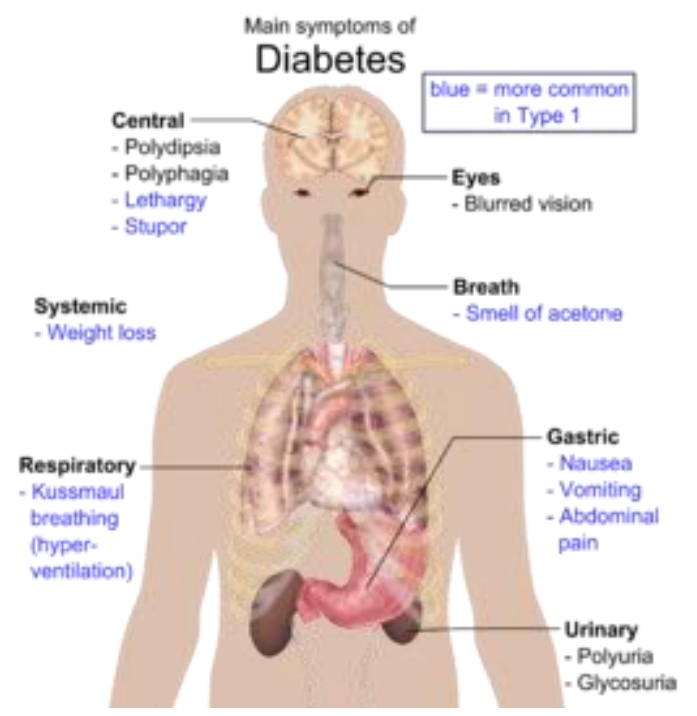

Overview of the most significant symptoms of diabetes. 
Main symptoms of

Acute HIV infection

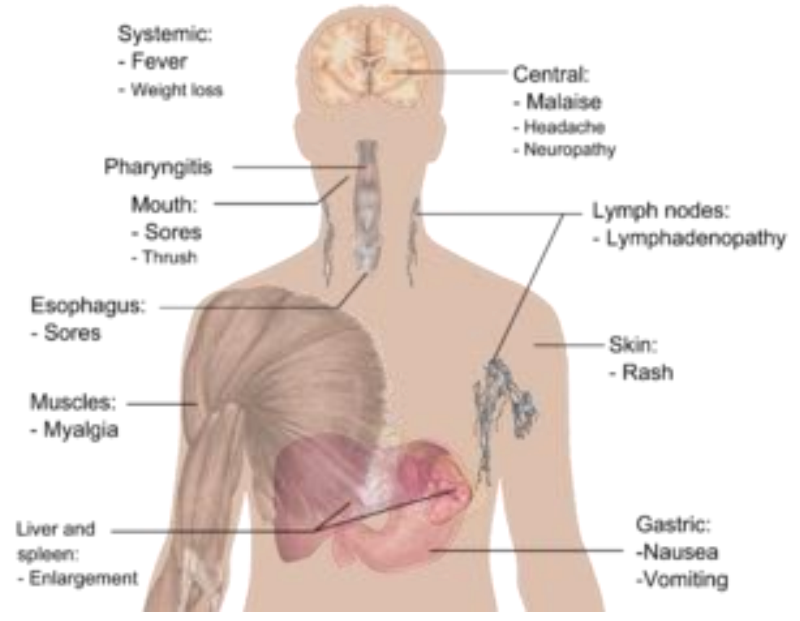

Main symptoms of acute HIV infection.

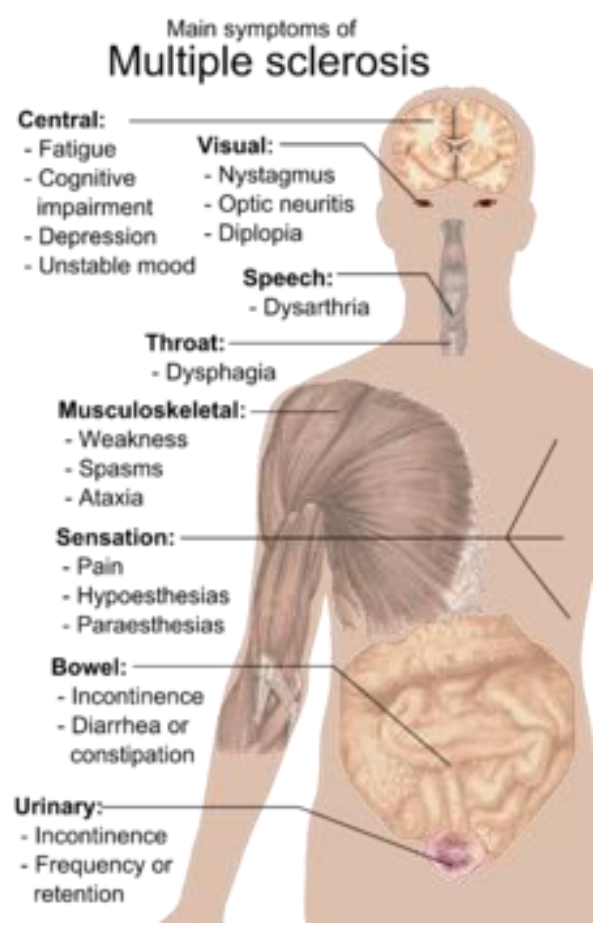

Main symptoms of multiple sclerosis. 


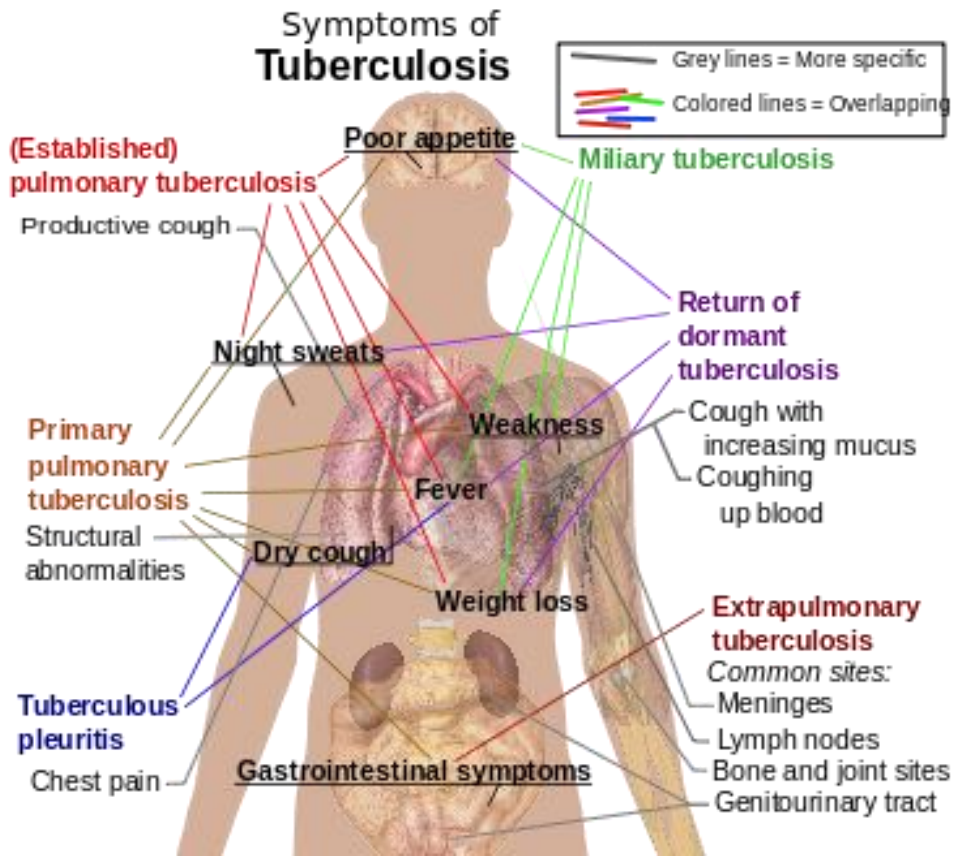

Comparison of symptoms of different variants and stages of tuberculosis. 


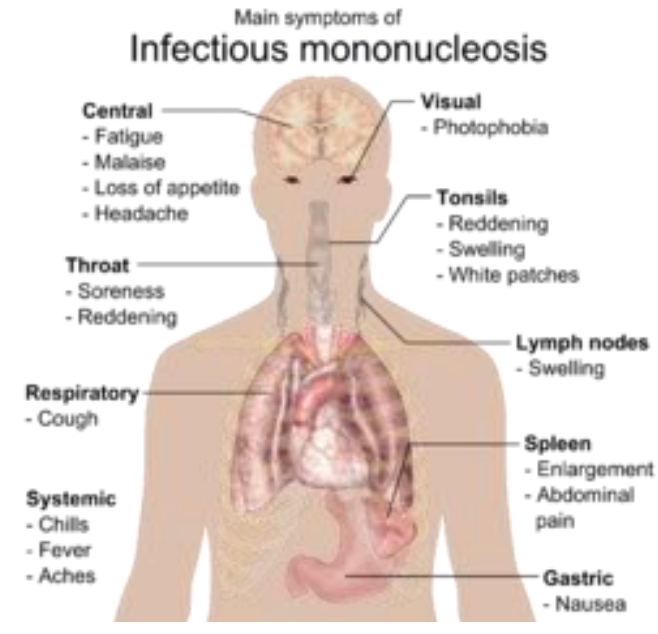

Main symptoms of infectious mononucleosis. ${ }^{[11]}[12][13]$

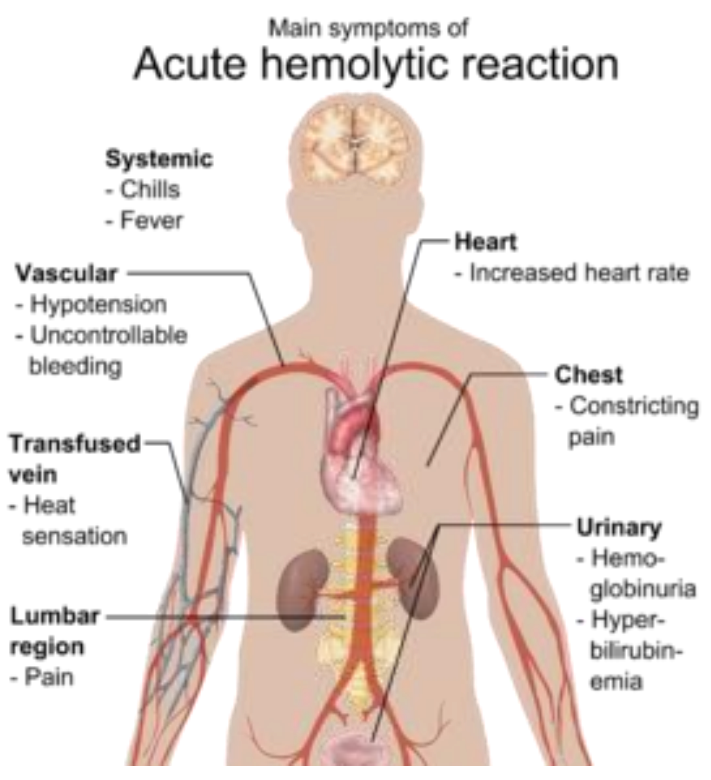

Main symptoms of acute hemolytic reaction due to blood type mismatch. ${ }^{[14][15]}$ 
Overview of

\section{Bacterial infections}

\begin{tabular}{|c|c|c|}
\hline $\begin{array}{l}\text { Pneumonia } \\
\text { Community-acquir } \\
\text { - Streptococcus pn } \\
\text { - Haemophilus infl } \\
\text { - Staphylococcus a } \\
\text { Atypical: } \\
\text { - Mycoplasma pne } \\
\text { - Chlamydia pneun } \\
\text { - Legionella pneum } \\
\text { Tuberculosis } \\
\text { - Mycobacterium } \\
\text { tuberculosis }\end{array}$ & $\begin{array}{l}\text { - Ureaplasma urealyticum } \\
\text { - Haemophilus ducreyl } \\
\text { Sexually transmitted } \\
\text { - Chlamydia trachomatis } \\
\text { - Neisseria ganornoeve } \\
\text { - Treponema pallidum } \\
\text { - }\end{array}$ & $\begin{array}{l}\text { - Staphylococcus aureus } \\
\text { - Neisseria gonormoeae } \\
\text { - Chlamydia trachomatis } \\
\text { - Sinusitis } \\
\text { - Streptococcus pneumoniae } \\
\text { - Haemophilus influenzae } \\
\text { - Upper respiratory tract } \\
\text { infection } \\
\text { - Streptococcus pyogenes } \\
\text { - Haemophilus influenzae } \\
\text { - Gastritis } \\
\text { - Helicobacter pylori } \\
\text { Food poisoning } \\
\text { - Campylobacter jejuni } \\
\text { - Salmonella } \\
\text { - Shigella } \\
\text { - Clostridium } \\
\text { - Staphylococcus } \\
\text { aureus } \\
\text { - Escherichia coli }\end{array}$ \\
\hline
\end{tabular}

Overview of bacterial infections and main species involved. ${ }^{[16][17]}$

\section{Overview of}

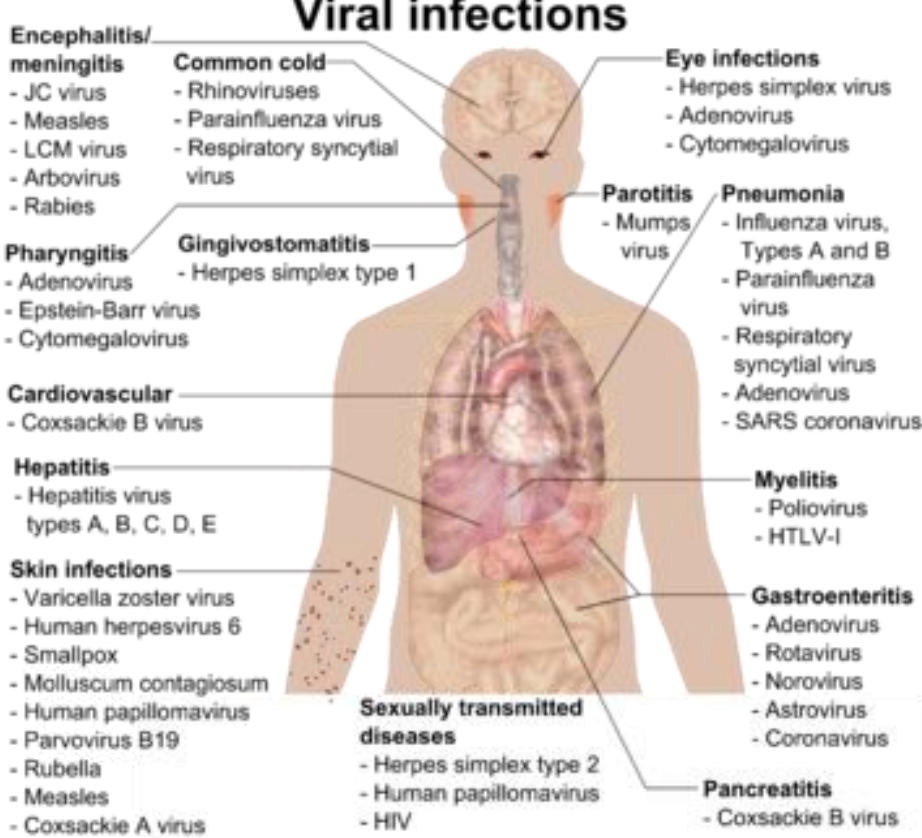

Overview of the main types of viral infection and the most notable species involved. ${ }^{[18]}$ [19] 


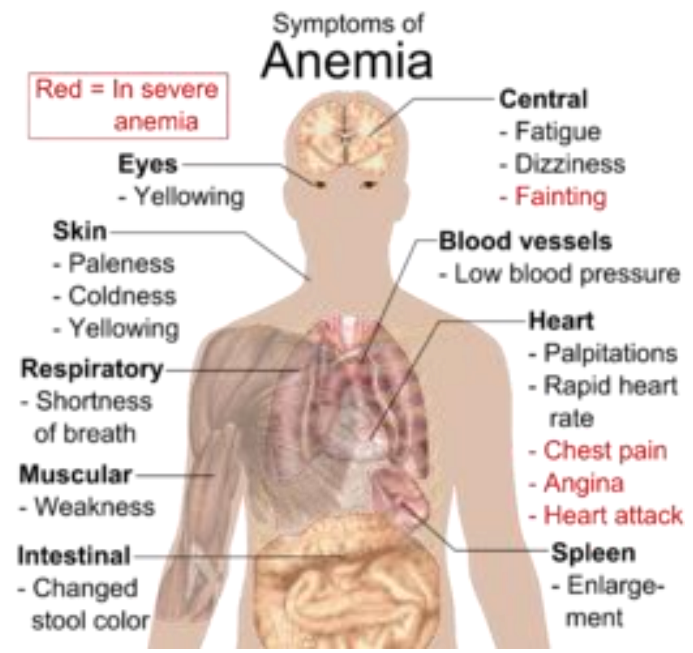

Main symptoms that may appear in anemia. ${ }^{[20]}$

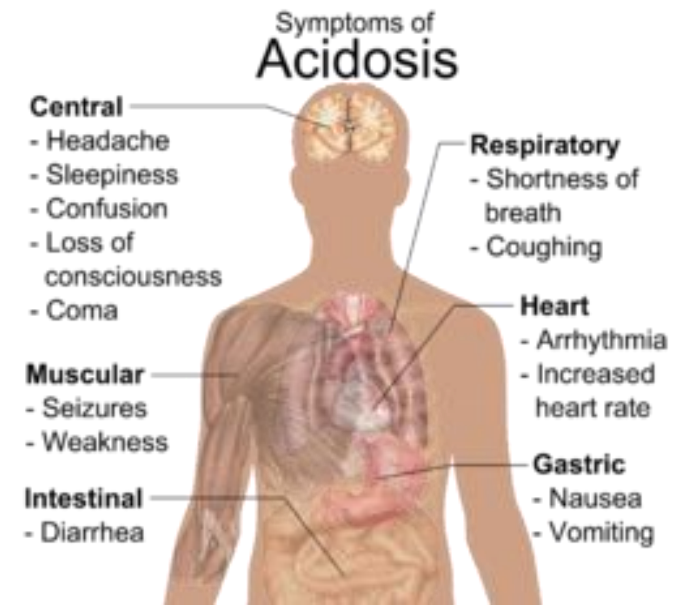

General symptoms of acidosis, ${ }^{[2]]}{ }^{[22]}$ resulting from decrease in body $\mathrm{pH}$. 


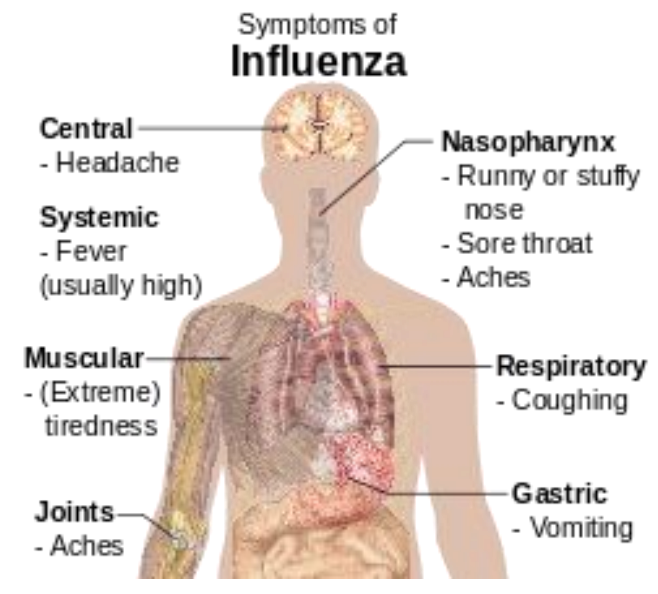

Main symptoms of influenza. ${ }^{[23]}$

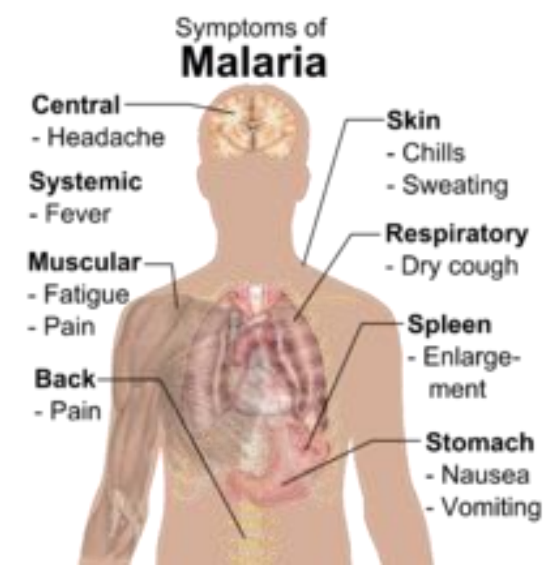

Main symptoms of malaria. ${ }^{[24]}$ 


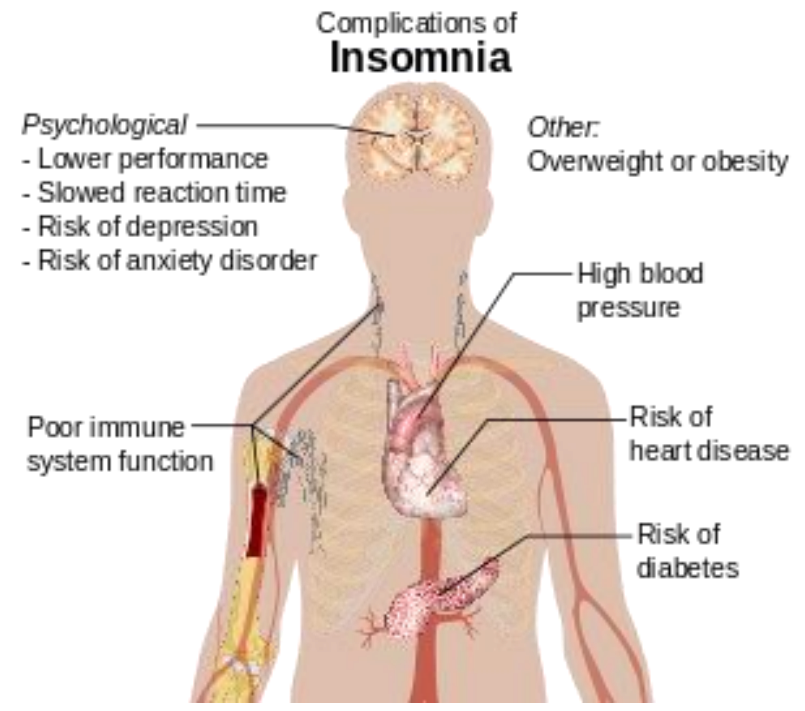

Potential complications of insomnia. ${ }^{[25]}$

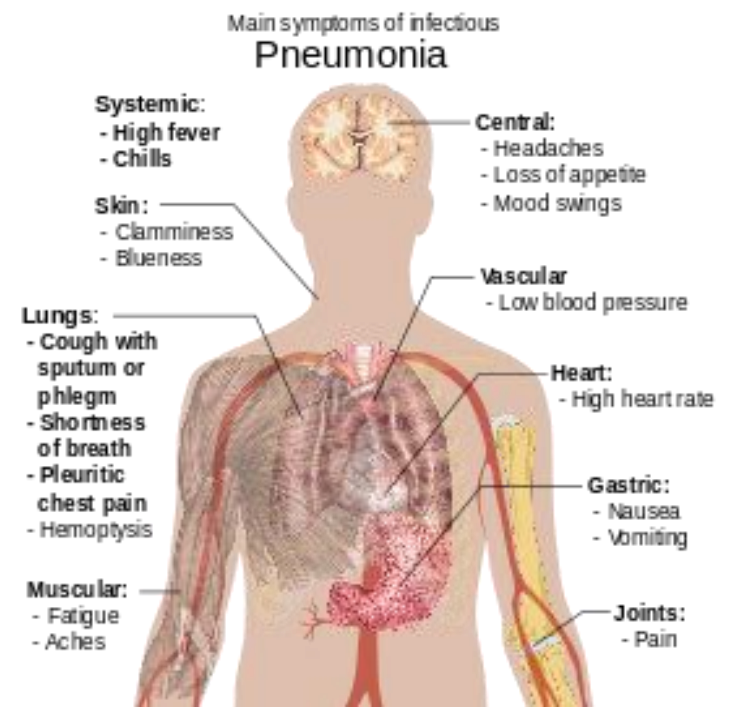

Main symptoms of infectious pneumonia. 
Signs and symptoms of

\section{Hypothyroidism}

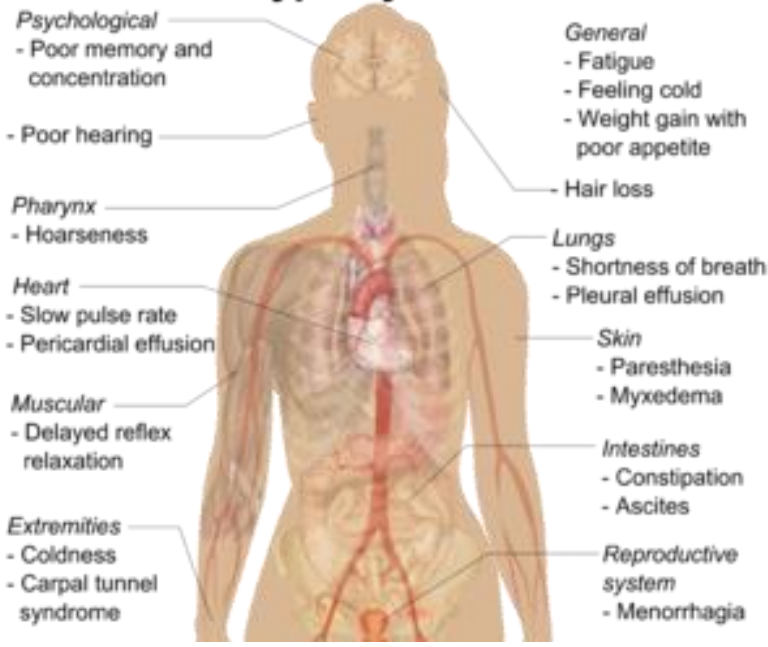

Signs and symptoms of hypothyroidism. ${ }^{[26]}$

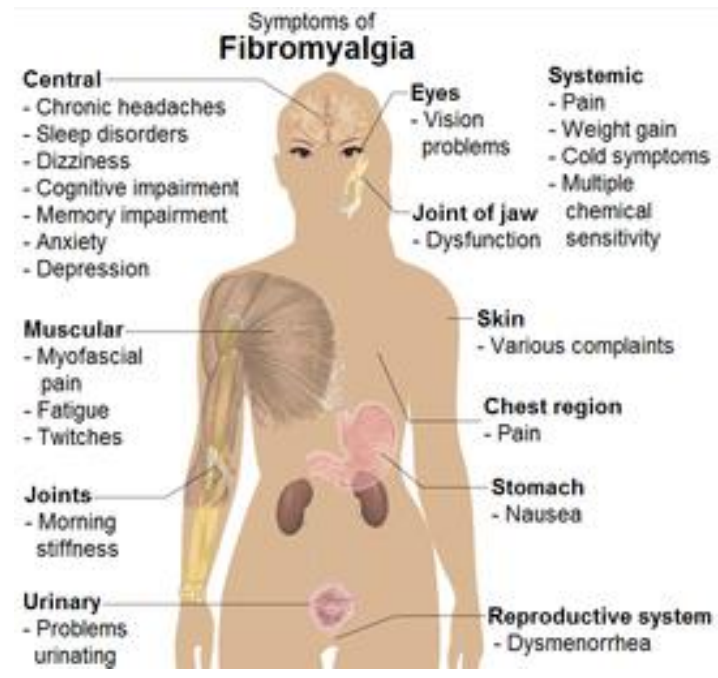

Symptoms of fibromyalgia. ${ }^{[27]}$ 


\section{Most common symptoms of \\ Systemic lupus erythematosus}

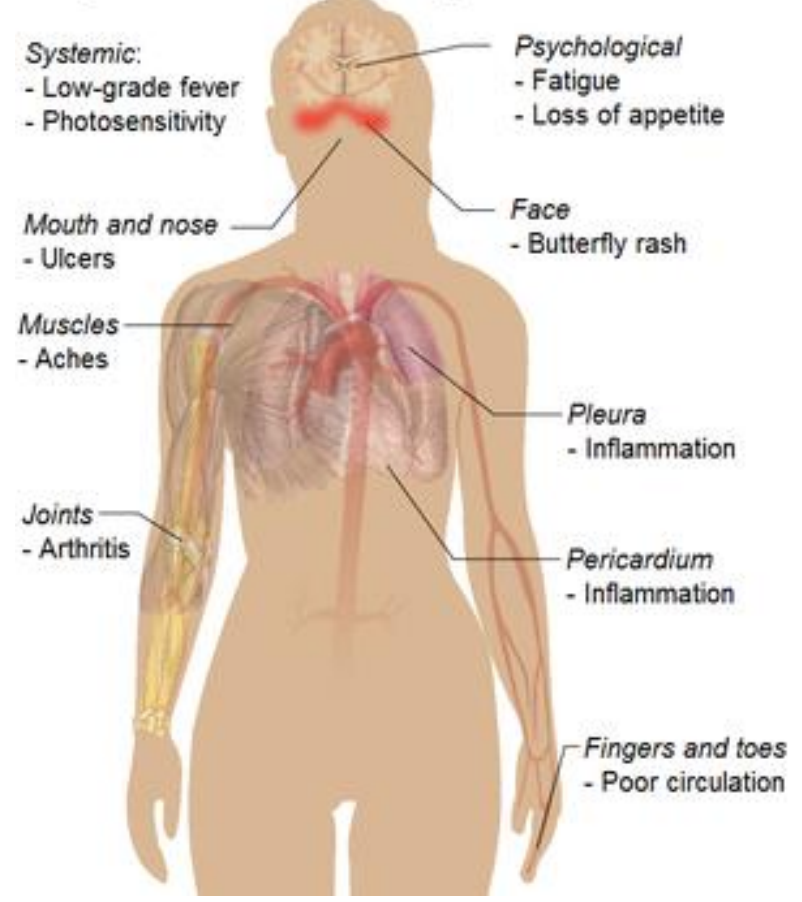

Symptoms of systemic lupus erythematosus. ${ }^{[28]}$ 


\section{Toxins}

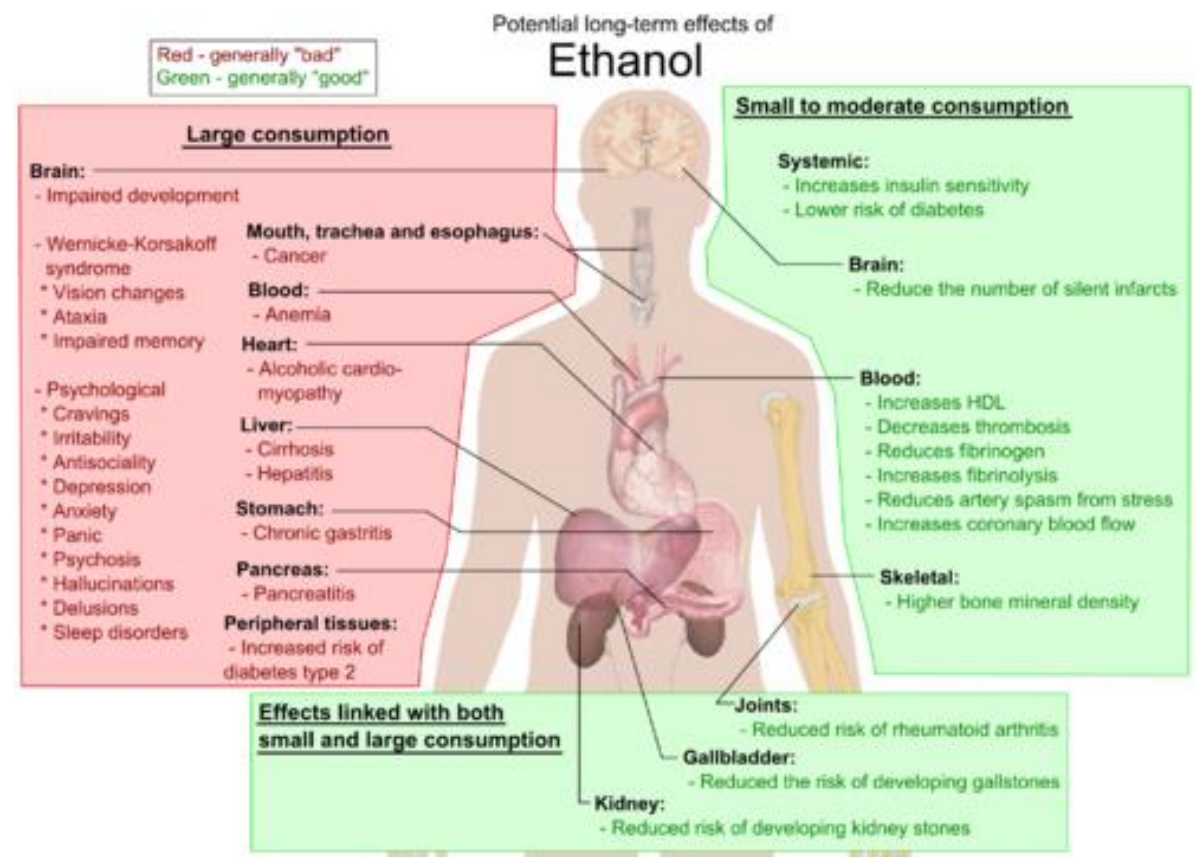

Most significant of the possible long-term effects of ethanol. Additionally, in pregnant women, it causes fetal alcohol syndrome.

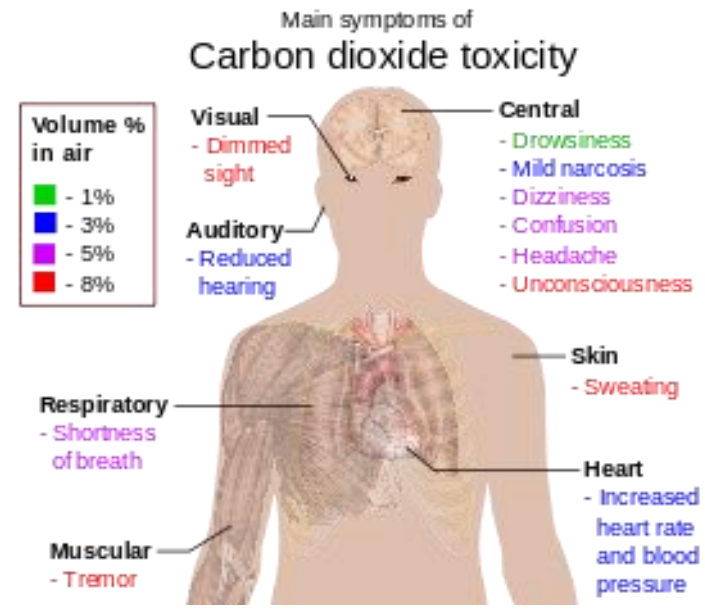

Main symptoms of carbon dioxide toxicity, by increasing volume percent in air. $\underline{\text { [29][30]. }}$. 


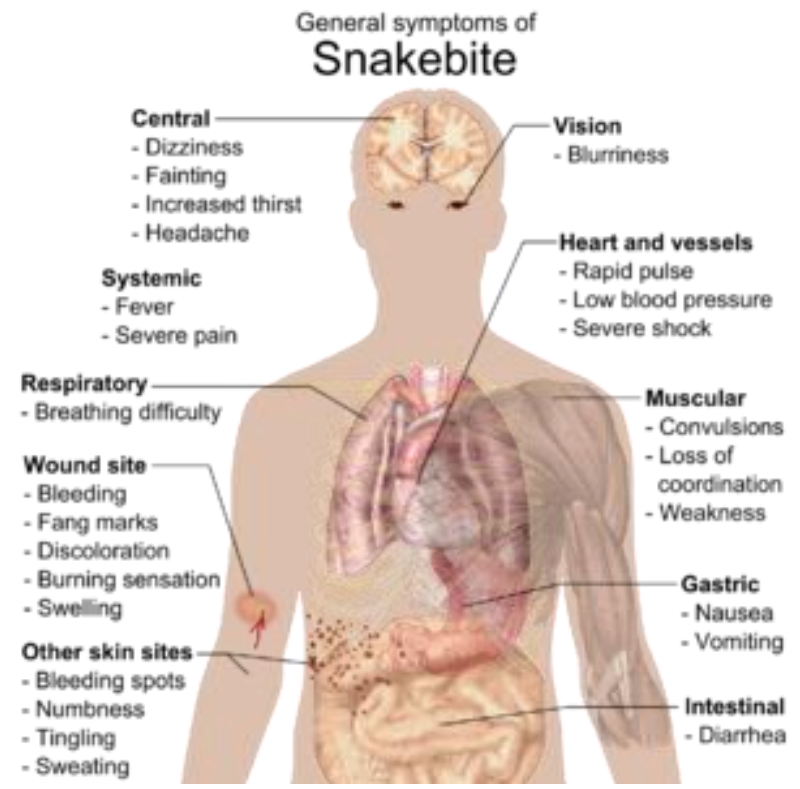

Most common symptoms of any kind of snake bite poisoning. ${ }^{[3]]}{ }^{[32]}{ }^{[33]}$ Furthermore, there is vast variation in symptoms between bites from different types of snakes. ${ }^{\left[{ }^{31]}\right.}$

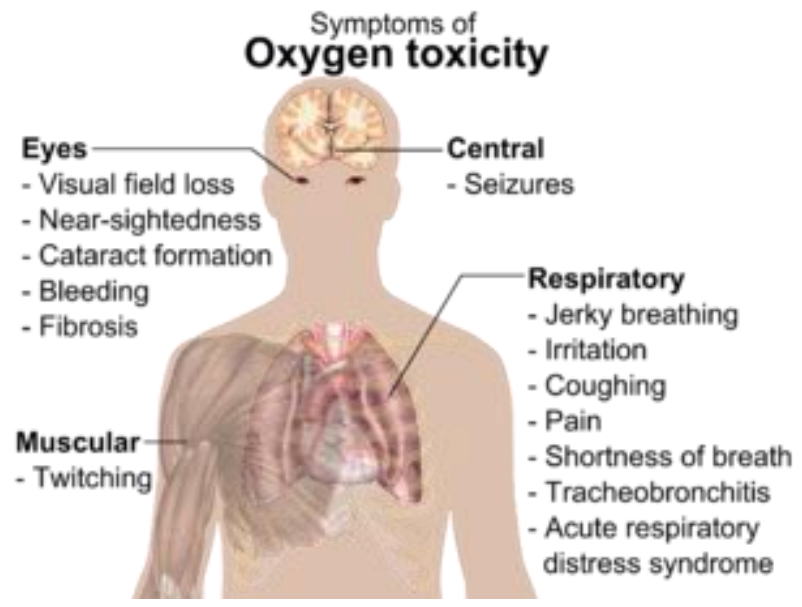

Main symptoms of oxygen toxicity. ${ }^{[37]}$ 


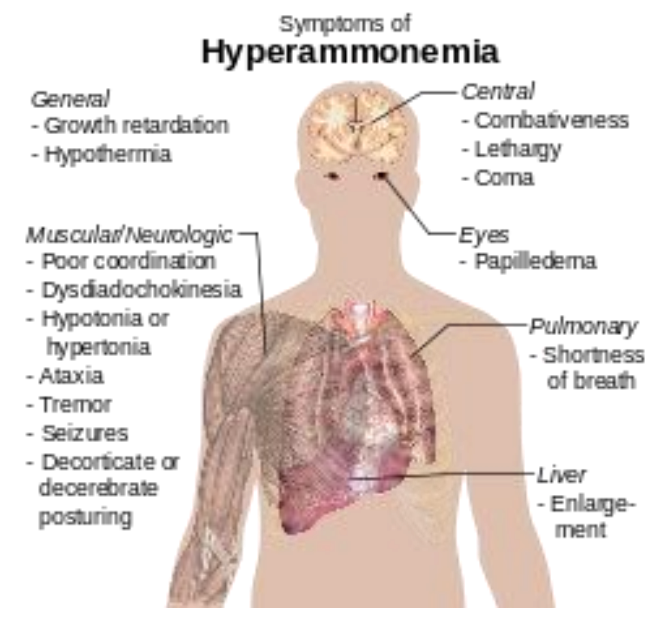

Main symptoms of hyperammonemia (ammonia reaching toxic concentrations). ${ }^{\left[{ }^{38]}\right.}$

\section{Tobacco smoking}

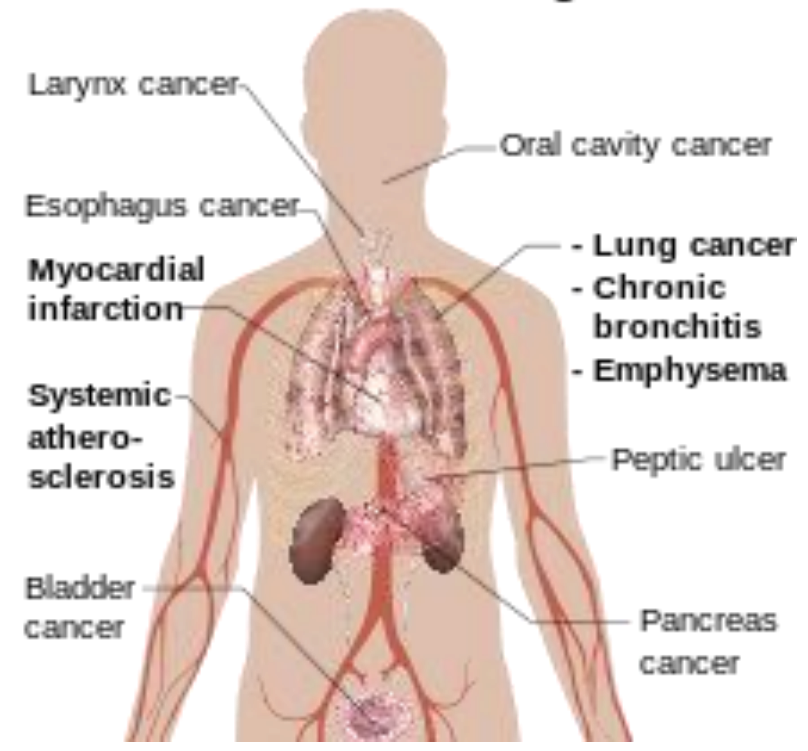

Common adverse effects of tobacco smoking. ${ }^{[39]}$ 


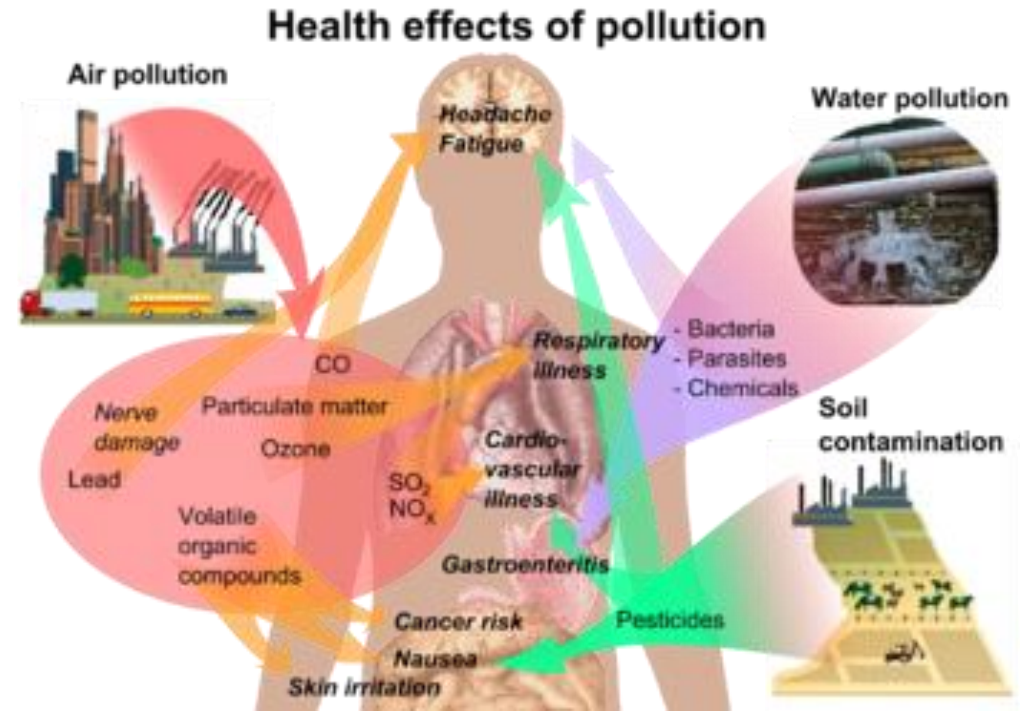

Overview of main health effects on humans from some common types of pollution. ${ }^{[34][35][36]}$

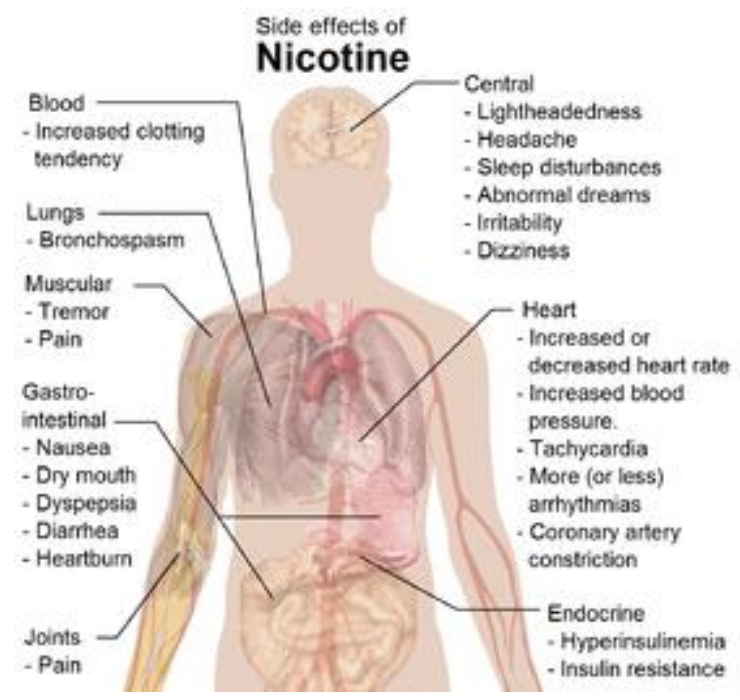

Side effects of nicotine. ${ }^{[40]}$ 


\section{Blood values}

Full length of images are found online.

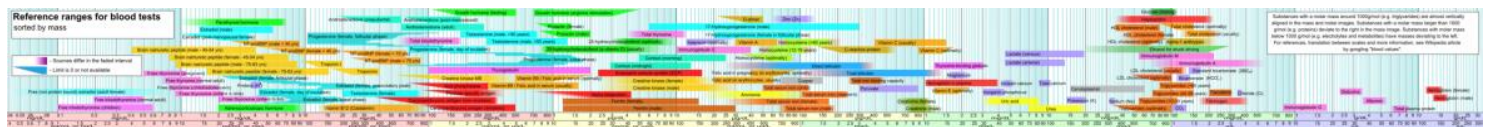

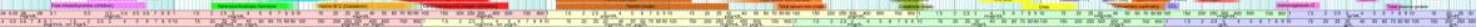
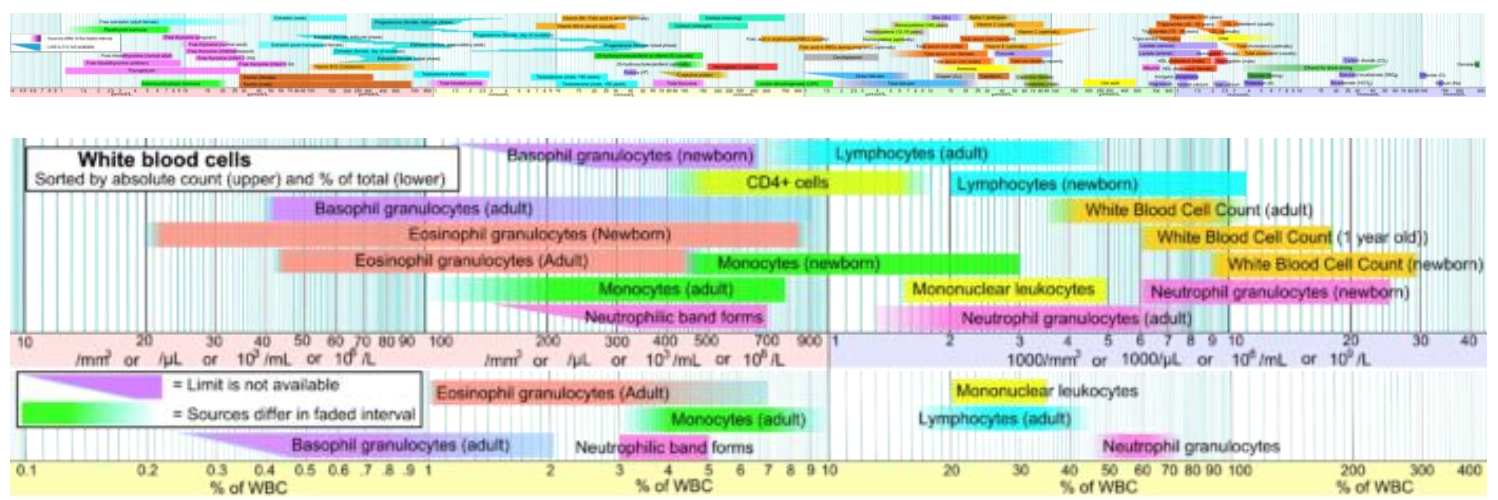

Reference ranges for blood tests, by units

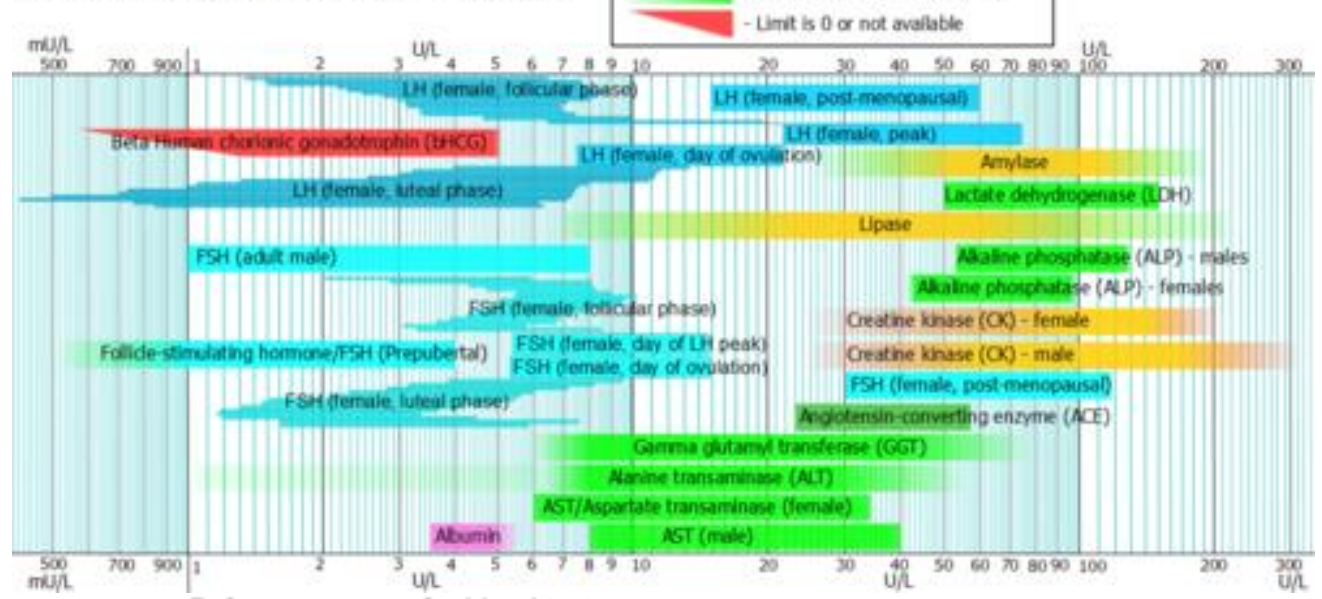

Reference ranges for blood tests

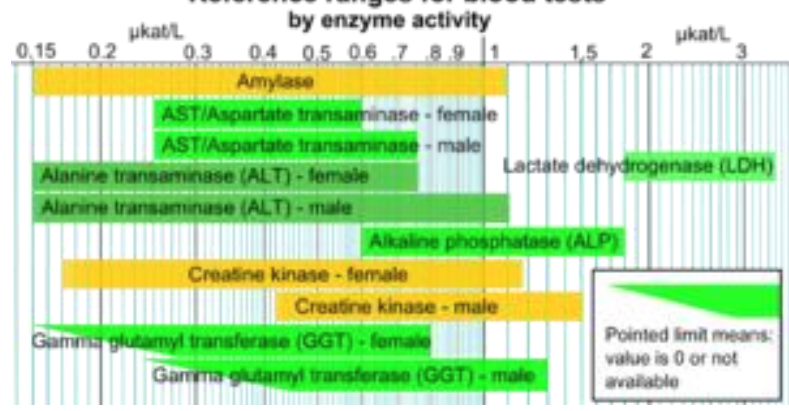




\section{Other medical diagrams}

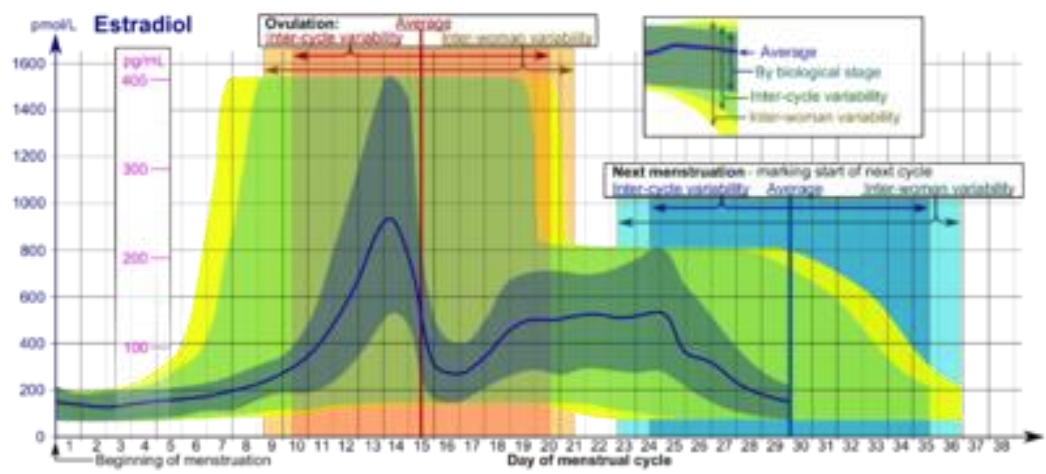

Estradiol during the menstrual cycle

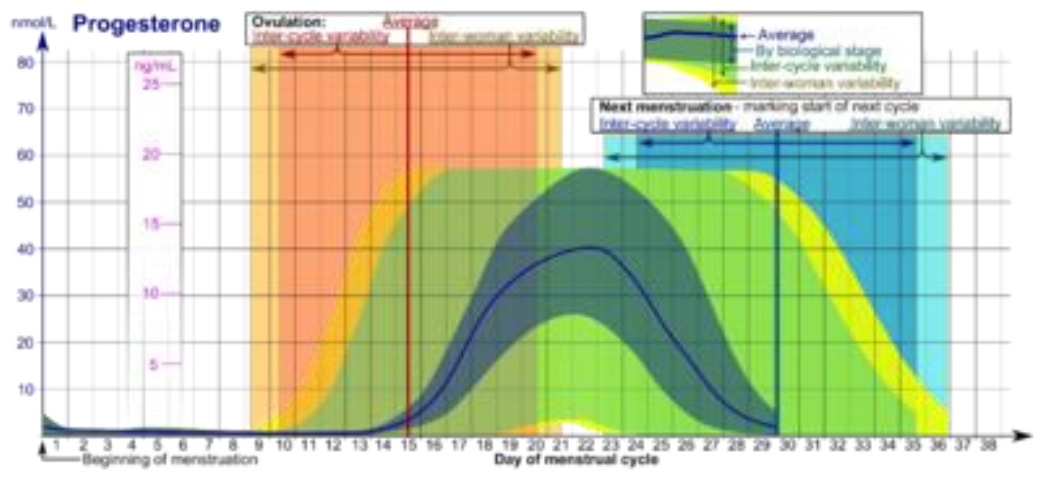

Progesterone during the menstrual cycle

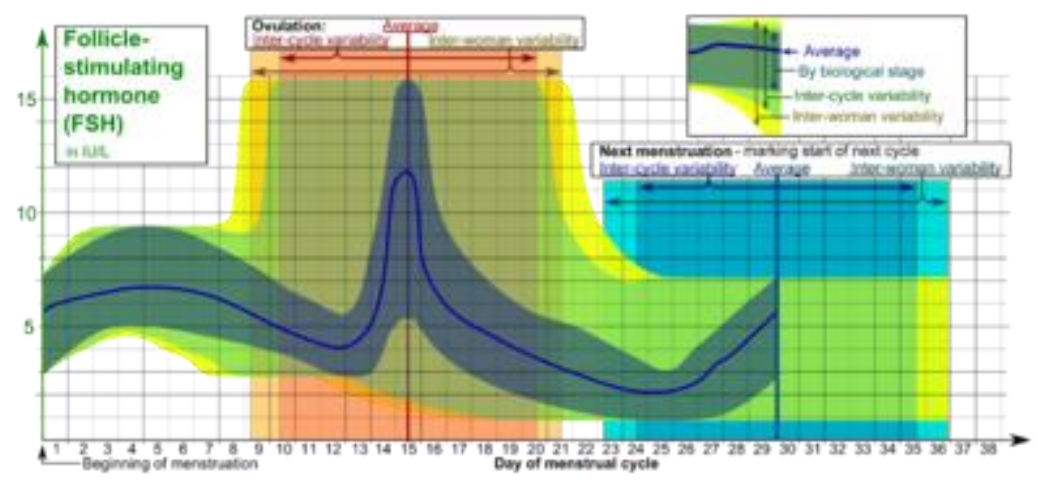

FSH during the menstrual cycle 


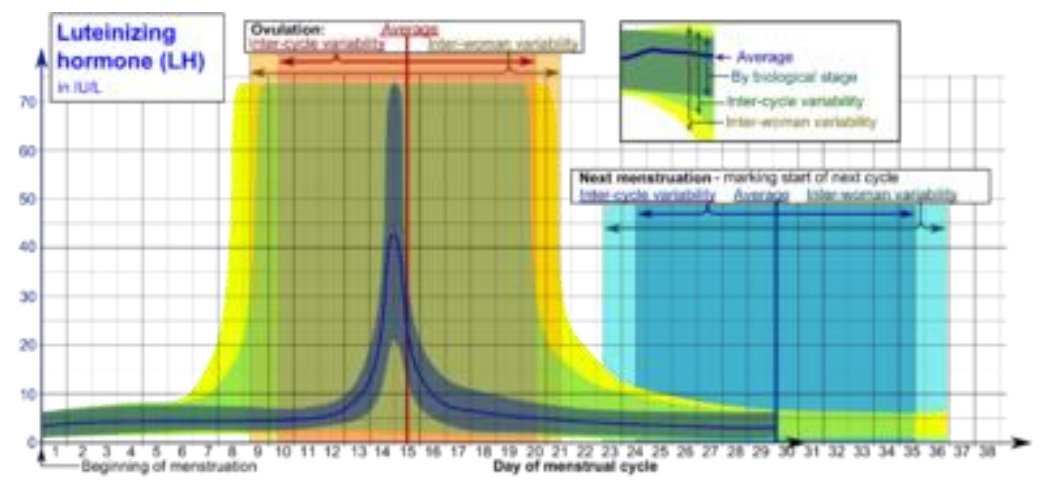

LH during the menstrual cycle

Incidence of ovarian cancers by histopathology

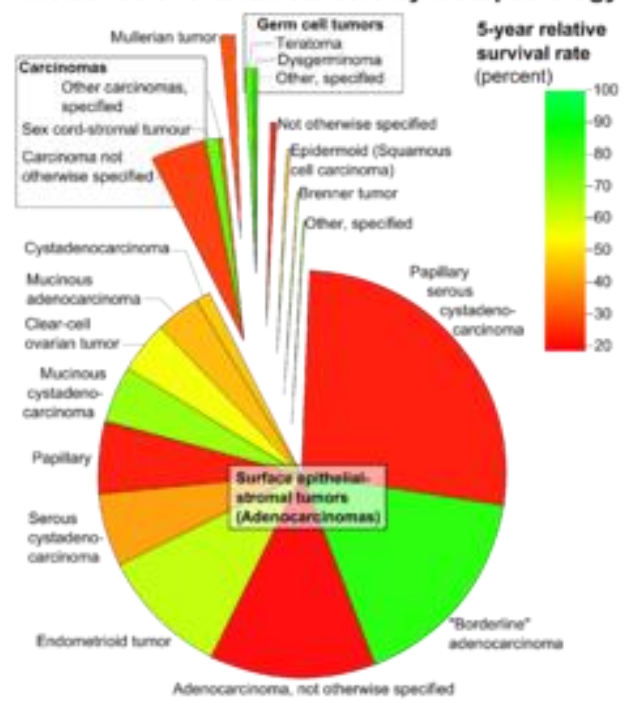

Incidence of ovarian cancers by histopathology

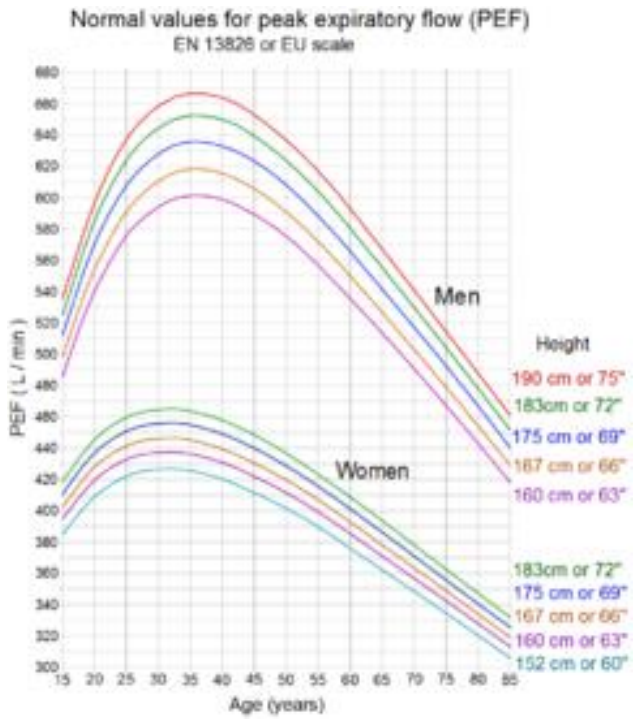

Normal values for peak expiratory flow

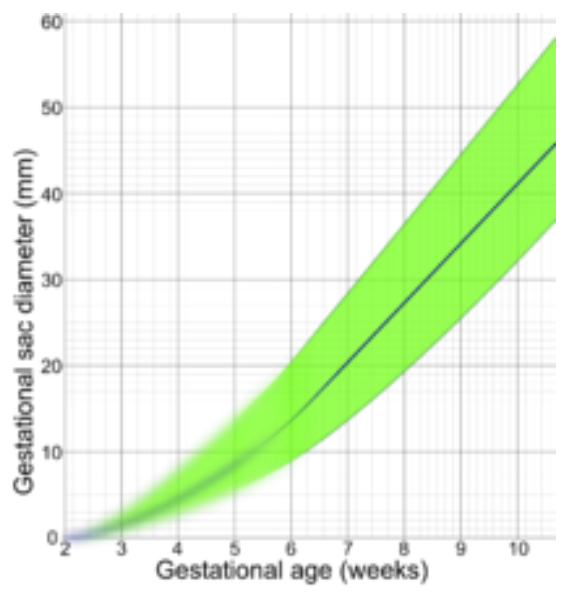

Gestational sac diameter by gestational age 


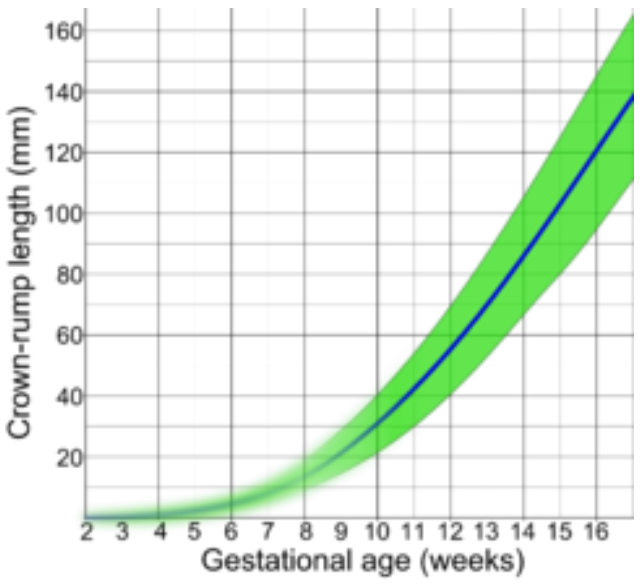

Crown-rump length by gestational age 


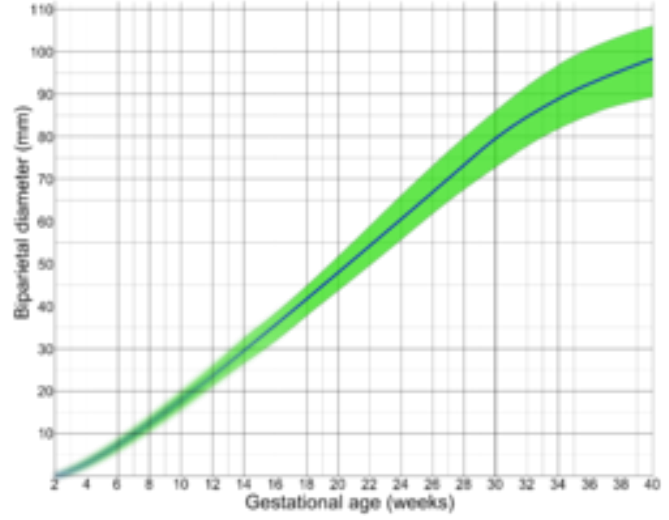

Biparietal diameter by gestational age

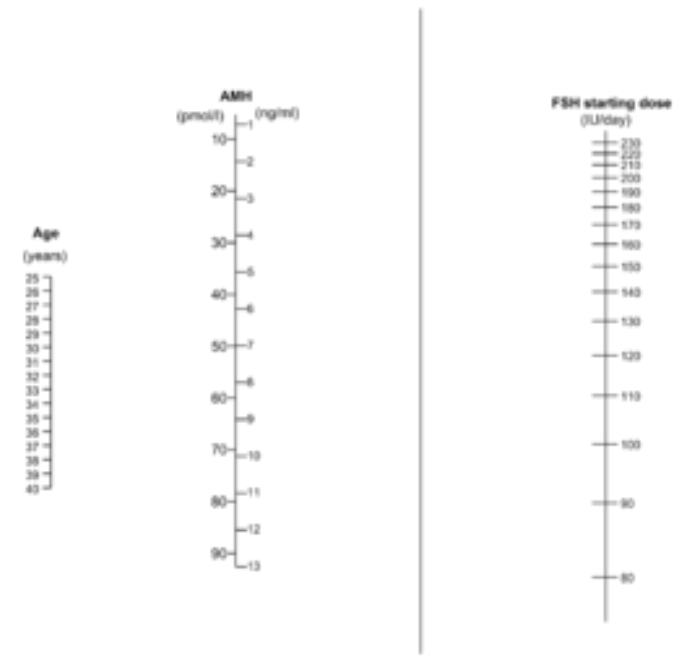

Dosage of FSH in hyperstimulation

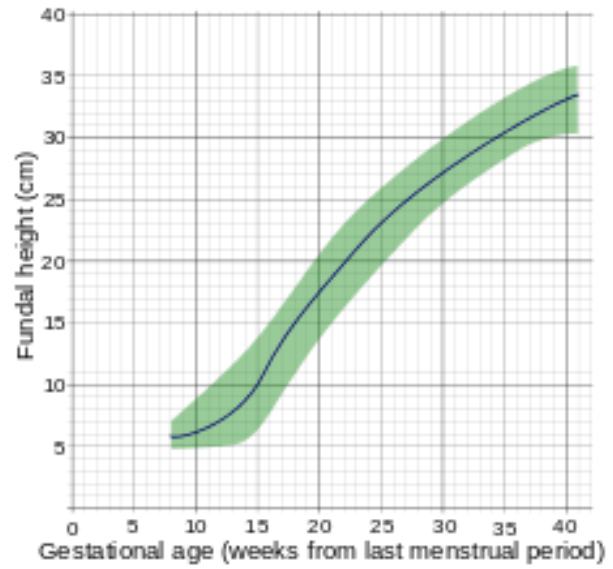

Fundal height by gestational age 


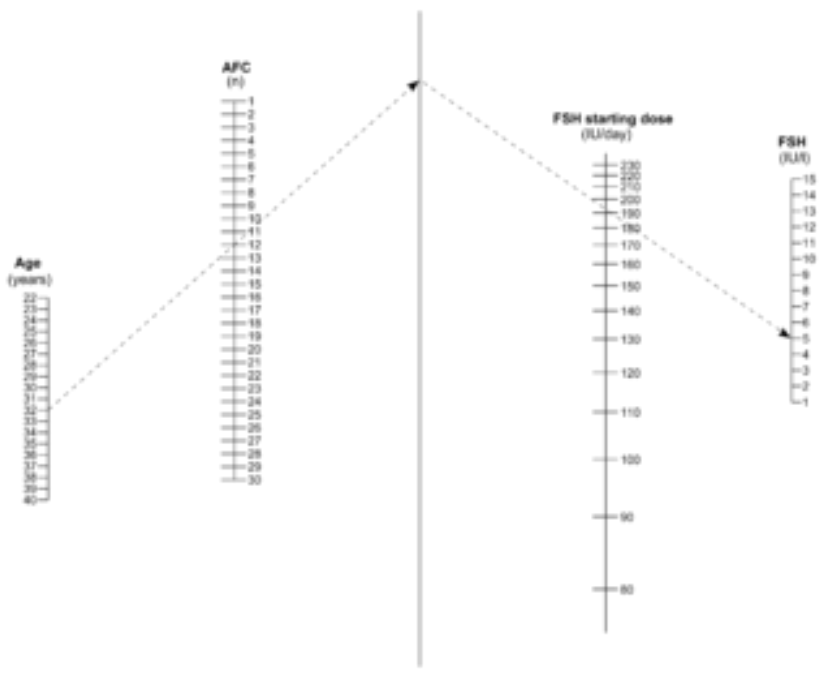

Dosage of FSH in hyperstimulation (using AFC instead of $\mathrm{AMH}$ )

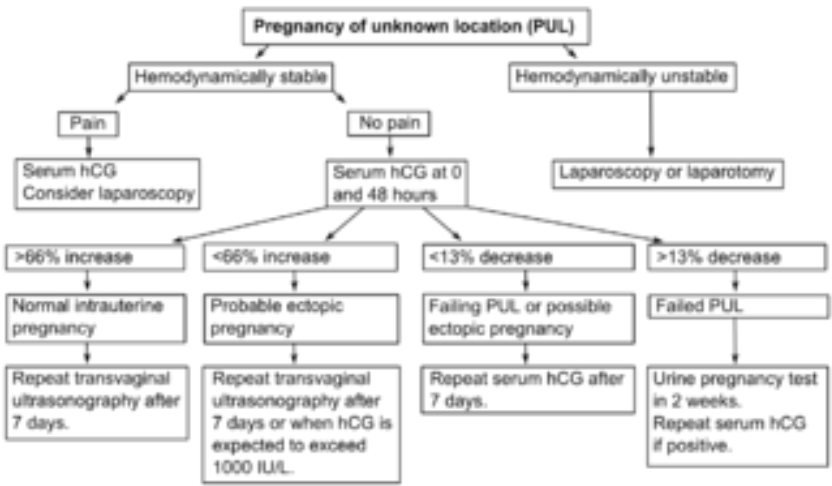

Algorithm in pregnancy of unknown location
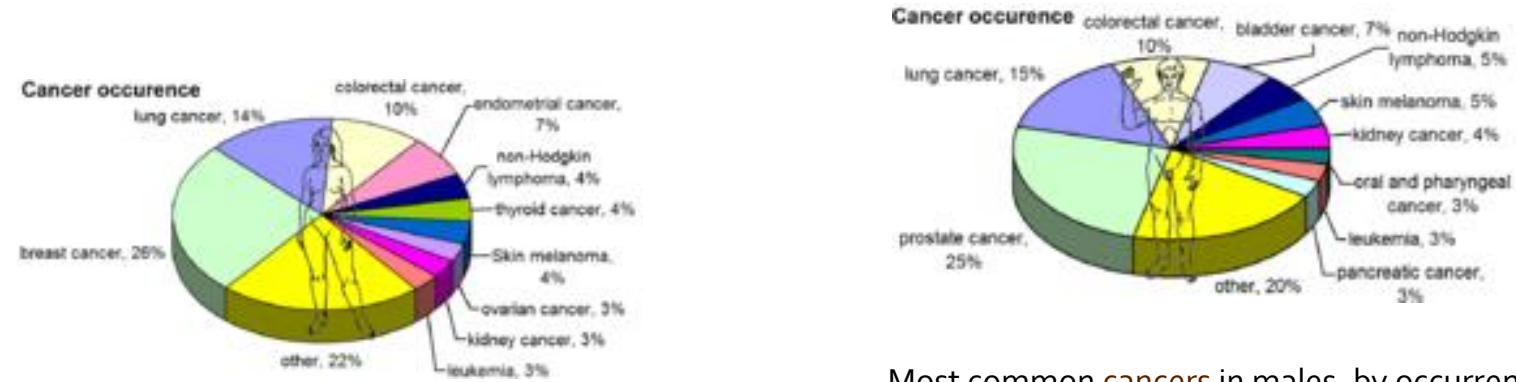

Most common cancers in males, by occurrence

Most common cancers in females, by occurence 


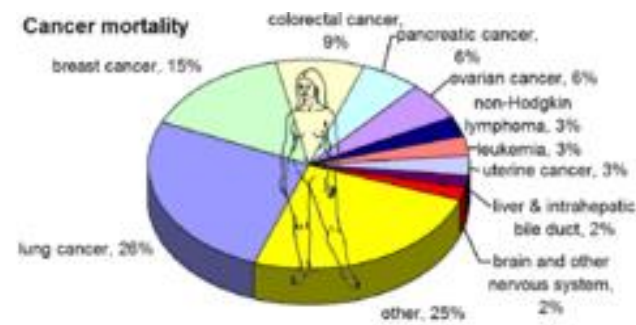

Most common cancers in females, by mortality

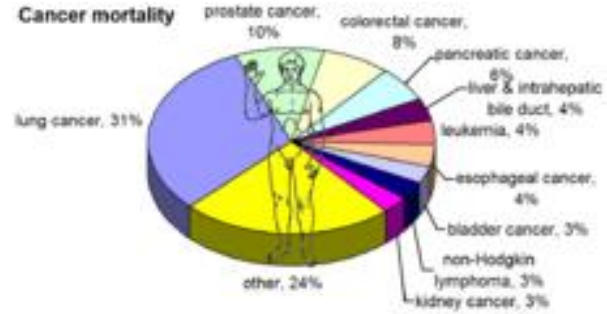

Most common cancers in males, by mortality

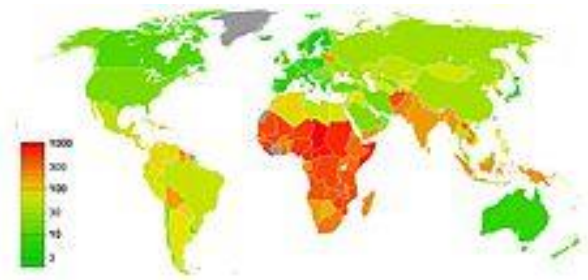

Maternal mortality rate worldwide

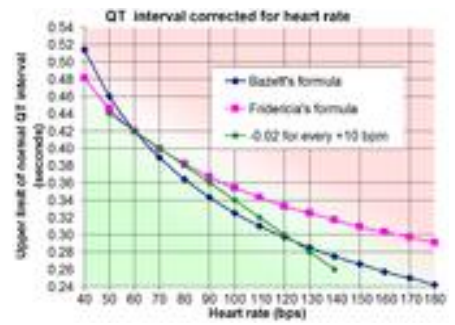

QT interval corrected for heart rate

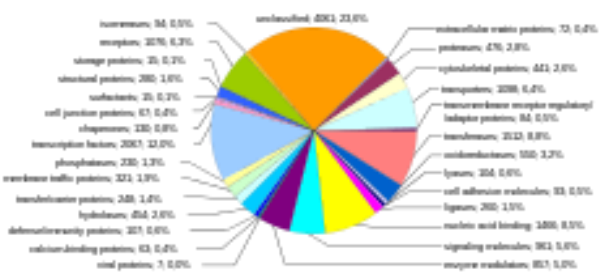

Human genome by functions

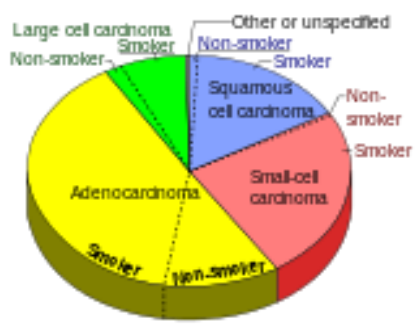

Lung cancer types

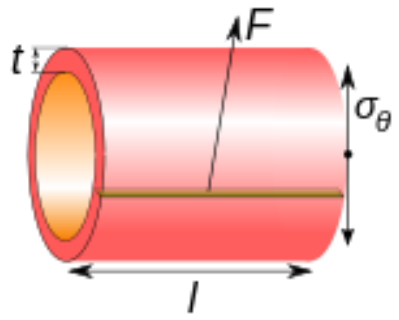

Circumferential stress

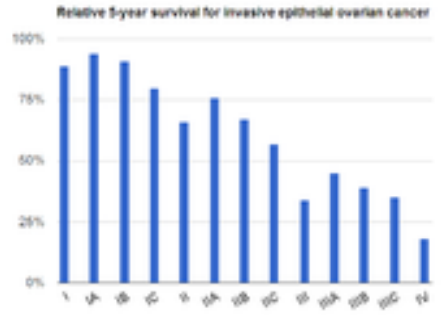

Relative survival in ovarian cancer 


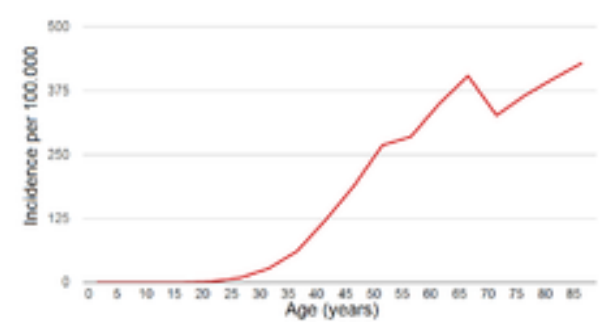

Breast cancer incidence by age

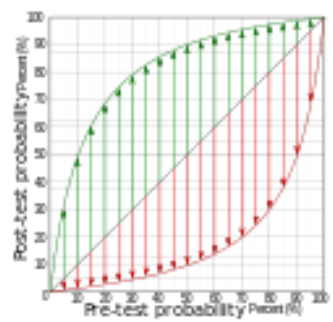

Pre- and posttest probabilities

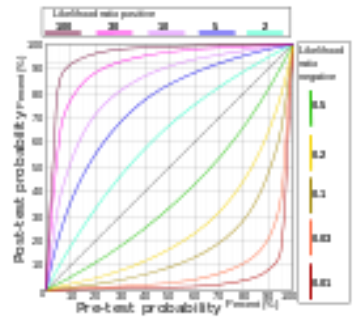

Pre- and post-test probabilities

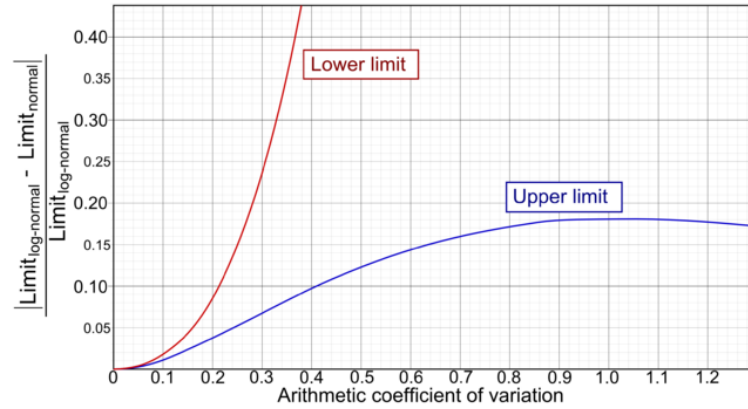

Coefficient of variation versus deviation in reference ranges "erroneously" not established by log-normal distribution

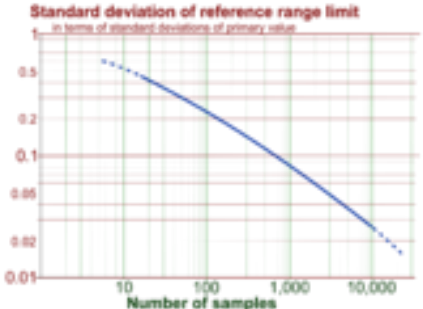

Standard deviation of standard reference range limit

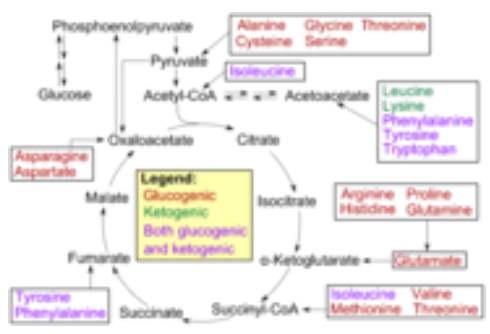

Amino acid catabolism

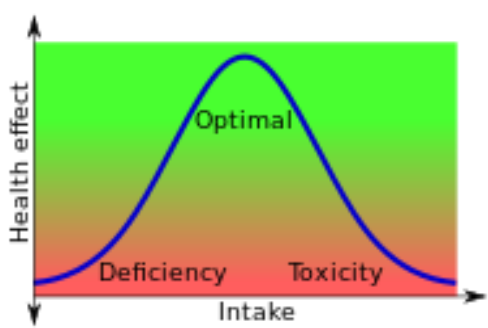

Bell curve of intake versus health effect 


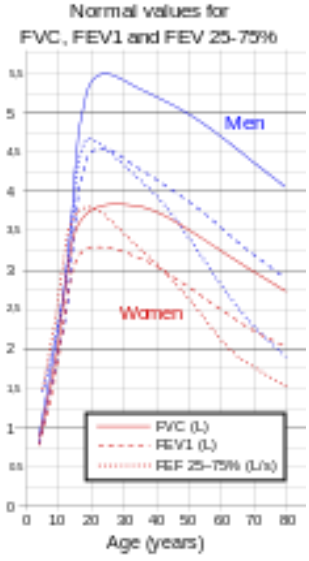

Normal values forForced Vital

Capacity(FVC), Forced Expiratory Volume in 1 Second (FEV 1 ) andForced Expiratory Flow 25$75 \%$ (FEF25-75\%).

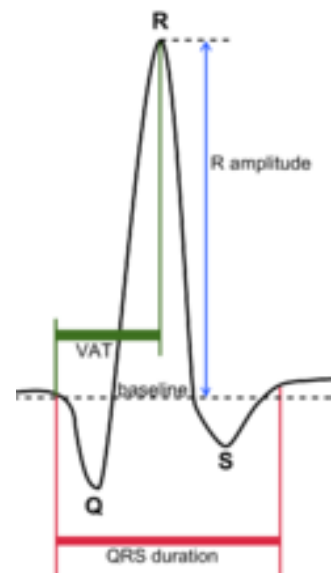

QRS complex

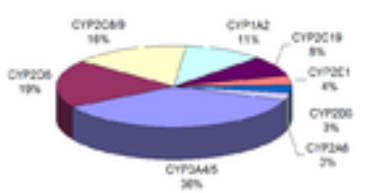

Proportion of drugs metabolized by differentCYPs

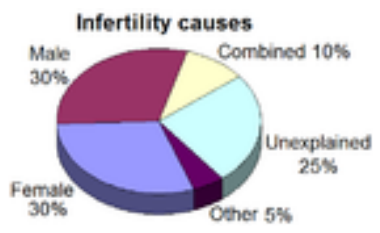

Causes of infertility

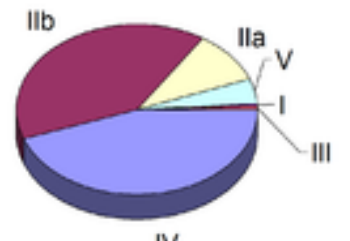

IV

Relative prevalence of familial

hyperlipoproteinemias

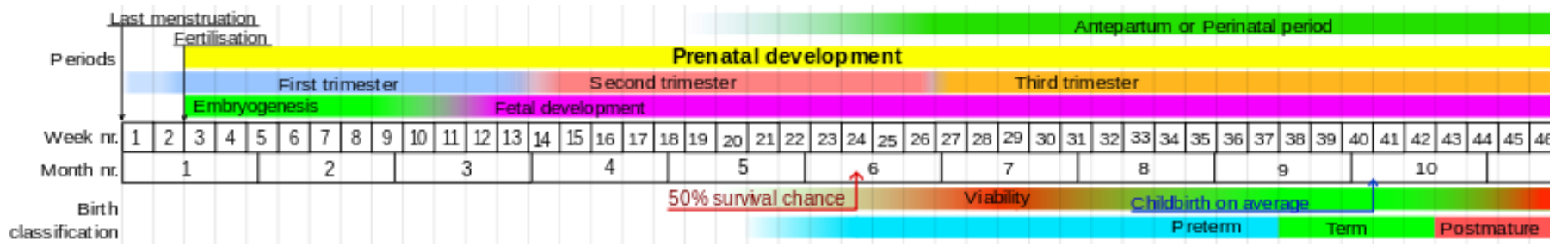


prenatal development.

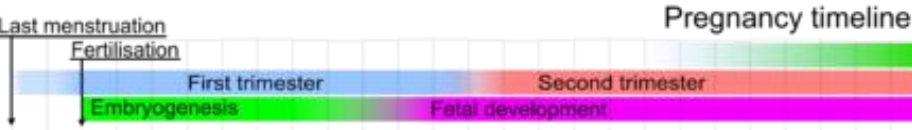

Pregnancy timeline.

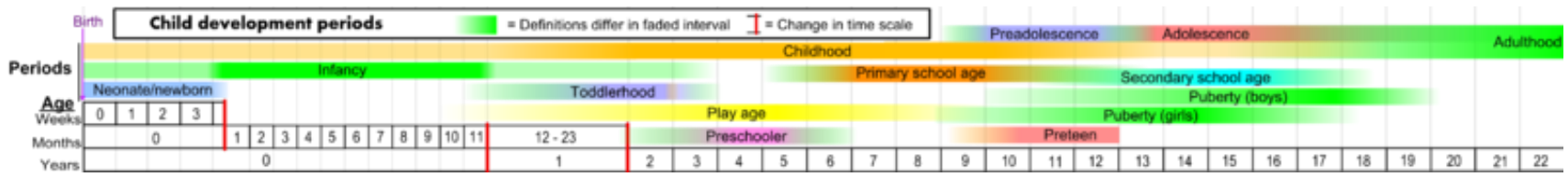

Child development stages.

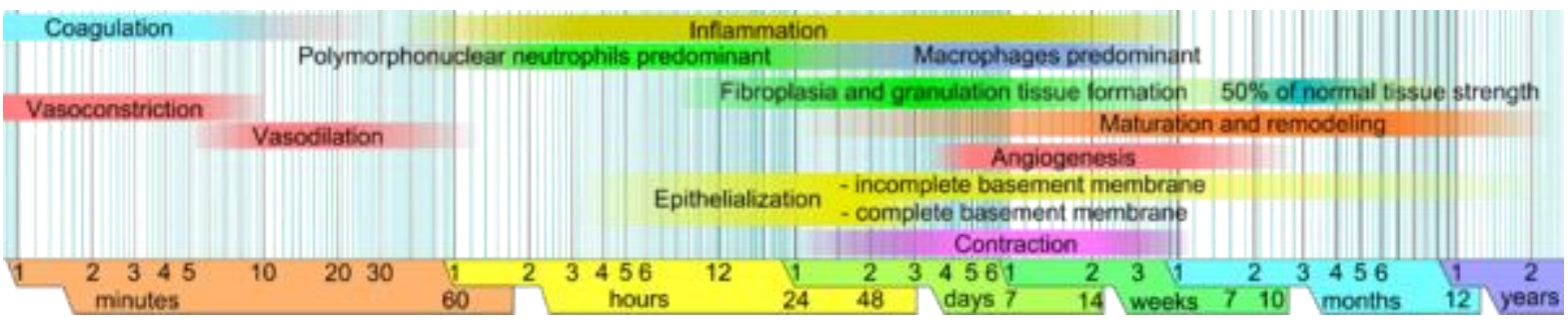

Wound healing phases. 


\section{Gray's Anatomy labeling}

The following images were taken from the now Public Domain version of Gray's anatomy from 1918, and were labeled for clarity.

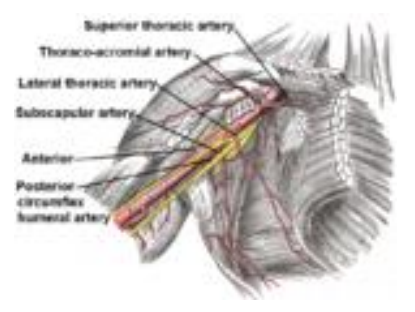

Axillary artery branches

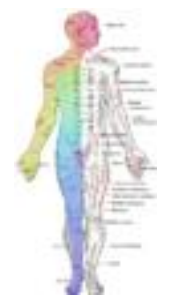

Dermatomes and cutaneou s nerves

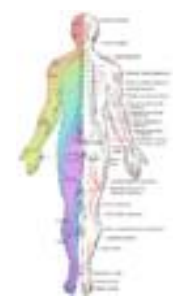

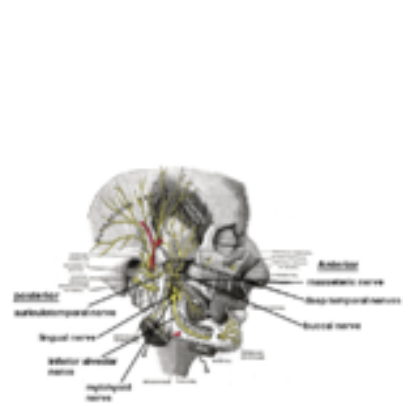

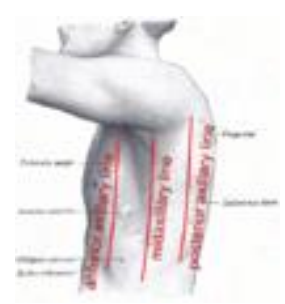

Axillary lines

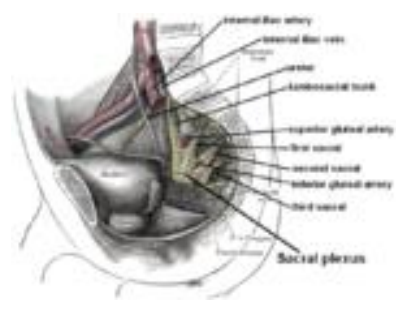

Sacral plexus

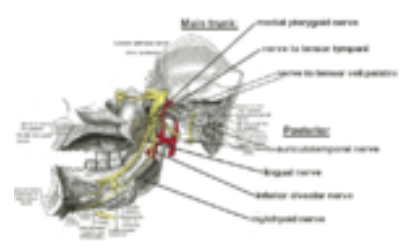

Mandibular nerve branches

Mandibular nerve branches

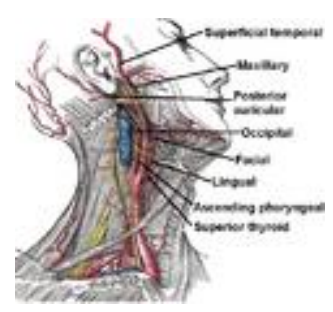

External carotid artery branches

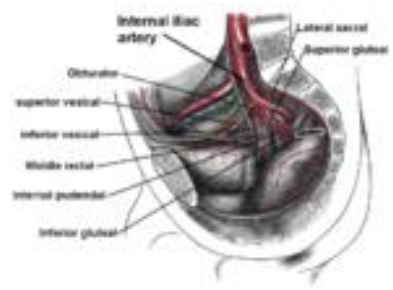

Internal iliac artery branches

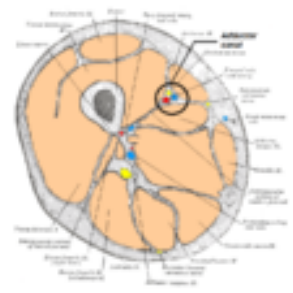

Adductor canal 


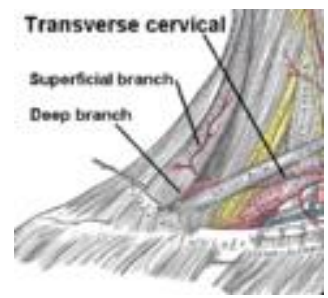

Superficial and deep

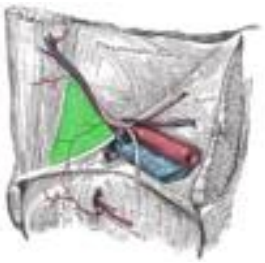

Inguinal triangle

branches of the transverse cervical artery

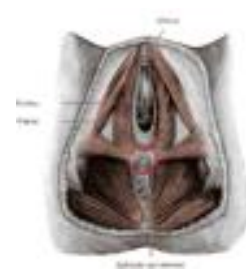

Perineal body

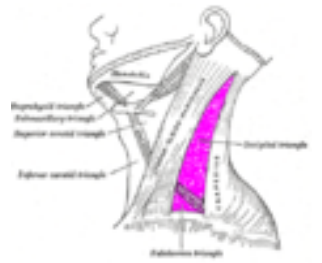

Posterior triangle of the neck

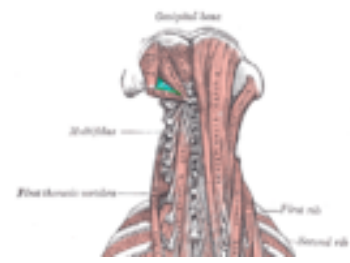

Suboccipital triangle

Frontal suture

Axillary space

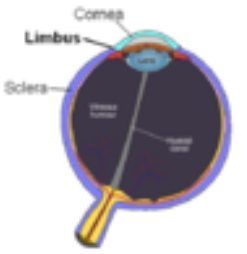

Limbus

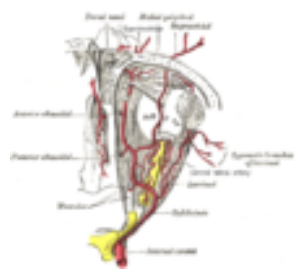

Arteries of the eye

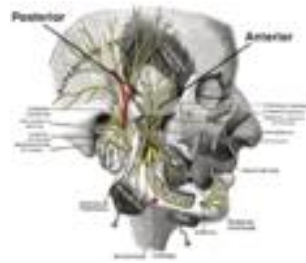

Deep temporal nerve

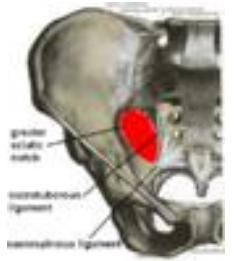

Greater sciatic foramen

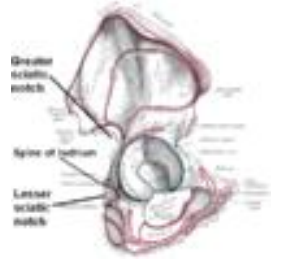

Sciatic notches 

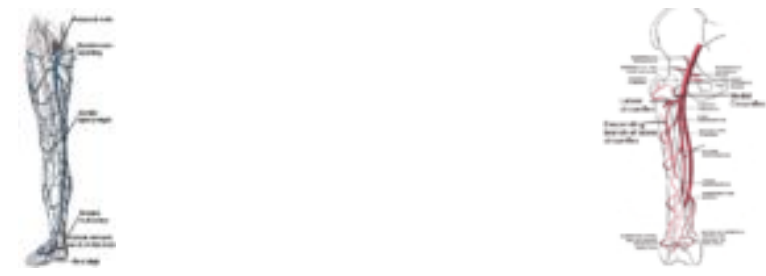

Great saphenous vein

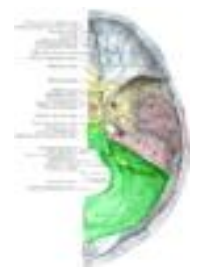

Posterior fossa

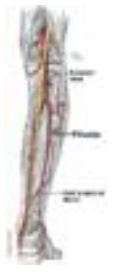

Fibular artery

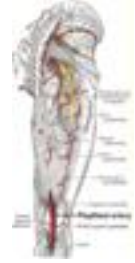

Popliteal artery

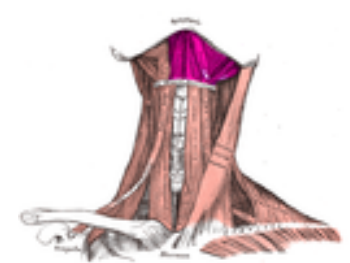

Suprahyoid muscles

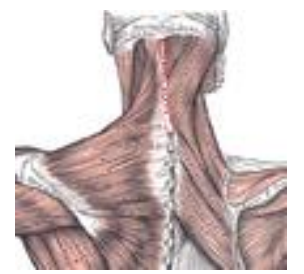

Nuchal ligament

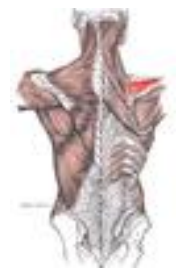

Supraspinatus muscle

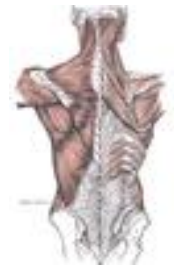

Lumbar triangle

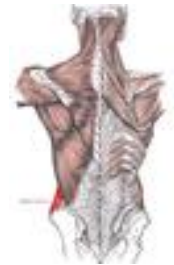

External oblique muscle

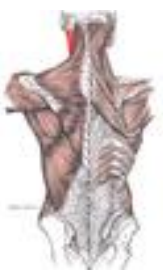

Sternocleidomastoid muscle 


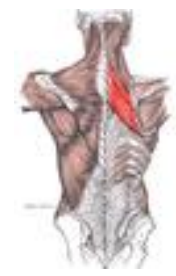

Rhomboid muscles

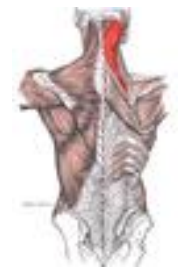

Splenius muscle

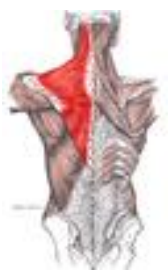

Trapezius muscle

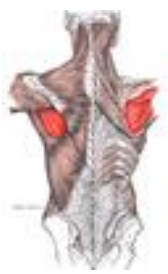

Infraspinatus muscle

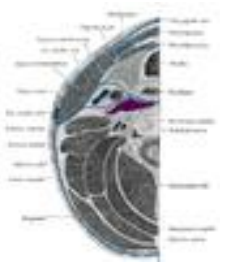

Prevertebral muscles

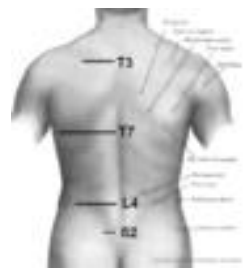

Orientation on the back

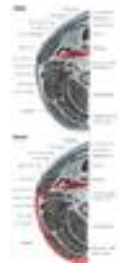

Prevertebral fascia

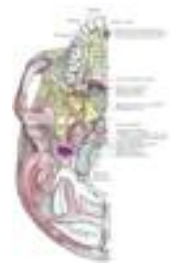

Jugular fossa

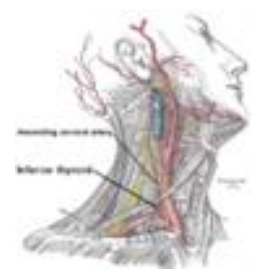

Inferior thyroid artery and ascending cervical artery

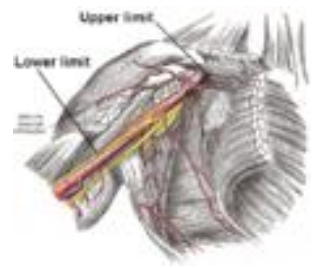

Limits of the axilla

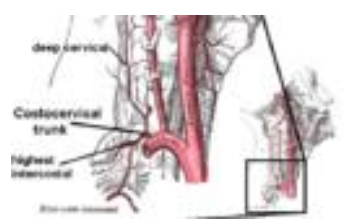

Costocervical trunk

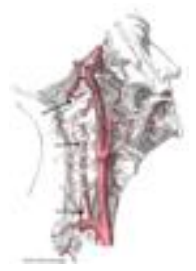

Vertebral artery 
궁

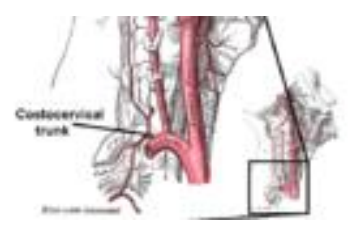

Costocervical trunk

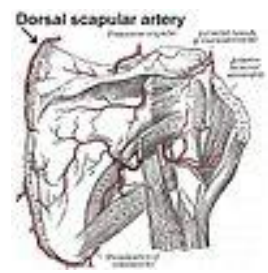

Dorsal scapular artery

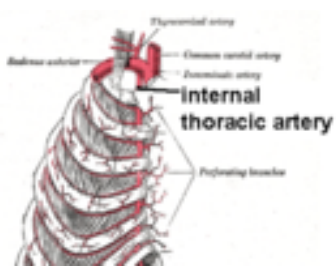

Internal mammary branch

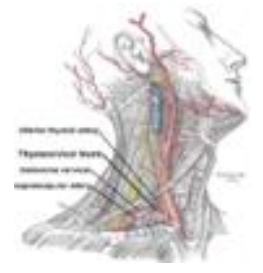

Thyrocervical trunk
WikiJournal of Medicine, 2014, 1(2) doi: $10.15347 / \mathrm{wjm} / 2014.008$

Figure Article
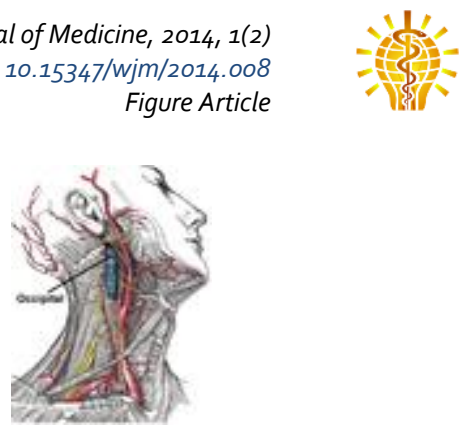

Subclavian arteries, first part

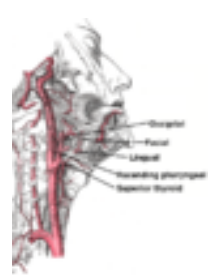

External maxillary artery branches

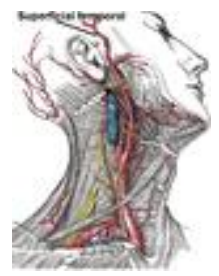

Superficial temporal artery

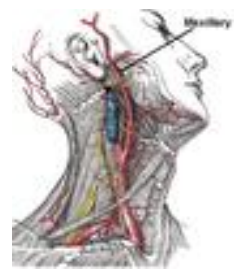

Maxillary artery

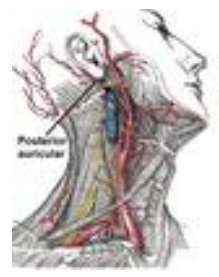

Posterior auricular artery

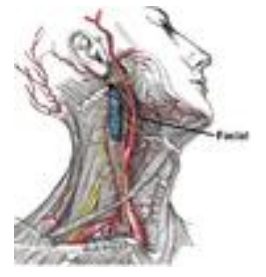

Facial artery

Occipital artery

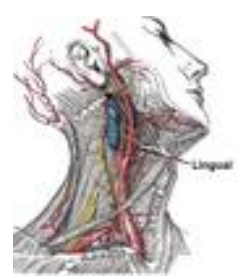

Lingual artery

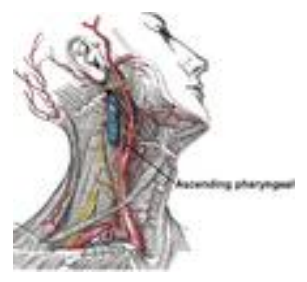

Ascending pharyngeal artery

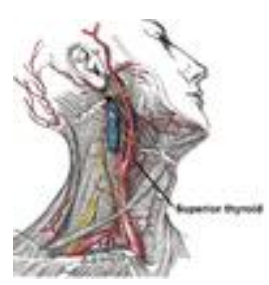

Superior thyroid artery 


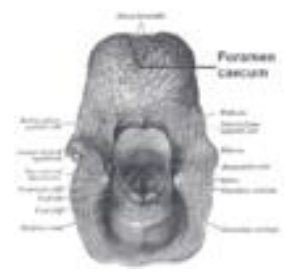

Foramen caecum

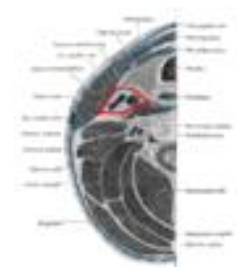

Carotid sheath

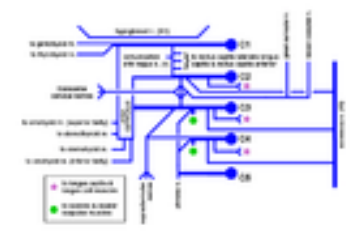

Cervical plexus

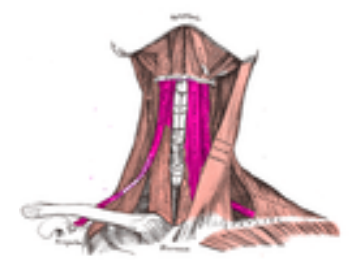

Infrahyoid muscles

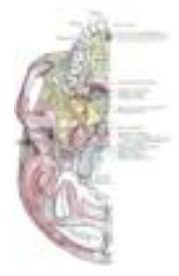

Petrotympanic fissure

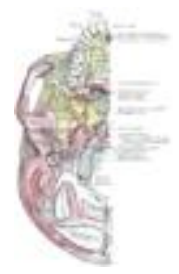

Stylomastoid foramen

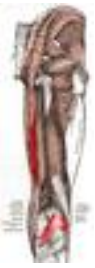

Semimembranosus muscle

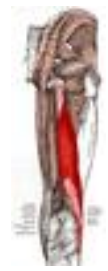

Biceps femoris muscle, long head

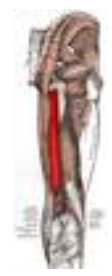

Semitendinosus muscle

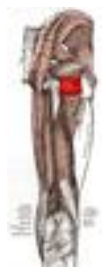

Quadratus femoris muscle

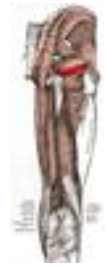

Inferior gemellus muscle

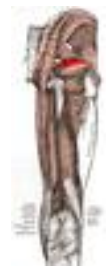

Gemellus superior muscle 

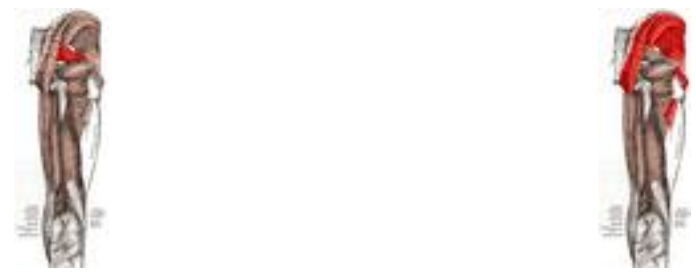

Piriformis muscle

Gluteus muscles

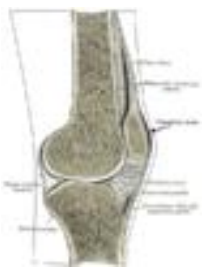

Prepatellar bursa

Gluteus medius muscle

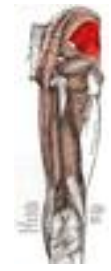

Gluteus minimus muscle

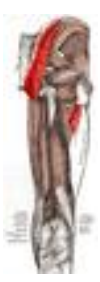

Gluteus maximus muscle

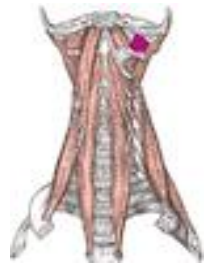
muscle

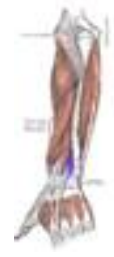

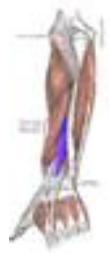

Extensor pollicis longus muscle

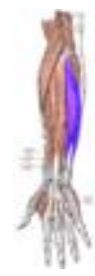

Extensor carpi ulnaris muscle

Rectus capitis lateralis

Extensor indicis muscle
Extensor digitorum muscle
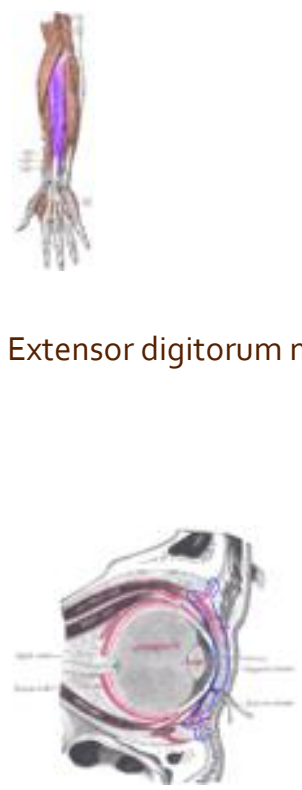

Orbital septum 


\section{References}

\section{Diabetes, rheumatoid arthritis, Parkinson's, Alzheimer's disease, osteoarthritis}

1. Cell Basics: What are the potential uses of human stem cells and the obstacles that must be overcome before these potential uses will be realized?. In Stem Cell Information World Wide Web site. Bethesda, MD: National Institutes of Health, U.S. Department of Health and Human Services, 2009. cited Sunday, April 26, 2009

\section{Stroke and traumatic brain injury repair}

2. Stem Cells Tapped to Replenish Organs thescientist.com, Nov 2000 By Douglas Steinberg

\section{Learning defects}

3. ISRAEL21C > Israeli scientists reverse brain birth defects using stem cells December 25, 2008. (Researchers from the Hebrew University of Jerusalem-Hadassah Medical led by Prof. Joseph Yanai)

\section{Spinal cord injury repair}

4. Kang KS, Kim SW, Oh YH, et al (2005). "A 37-year-old spinal cordinjured female patient, transplanted of multipotent stem cells from human UC blood, with improved sensory perception and mobility, both functionally and morphologically: a case study". Cytotherapy 7 (4): 368-73. doi:10.1080/14653240500238160. PMID 16162459

\section{Heart infarction}

5. Straver BE, Schannwell CM, Brehm M (April 2009). "Therapeutic potentials of stem cells in cardiac diseases". Minerva Cardioangiol 57 (2): 249-67. PMID 19274033.

\section{Anti-cancer}

6. Stem Cells Tapped to Replenish Organs thescientist.com, Nov 2000. By Douglas Steinberg

\section{Baldness}

7. Hair Cloning Nears Reality as Baldness Cure WebMD November 2004

\section{Replace missing teeth}

8. Yen AH, Sharpe PT (January 2008). "Stem cells and tooth tissue engineering". Cell Tissue Res. 331 (1): 359-72. doi:10.1007/s00441-0070467-6. PMID 17938970.

\section{Repair hearing}

9. Gene therapy is first deafness 'cure' - health - 14 February 2005 - New Scientist

\section{Restore vision}

10. BBC NEWS | England | Southern Counties | Stem cells used to restore vision

\section{Amyotrophic lateral sclerosis}

11. Drs. Gearhart and Kerr of Johns Hopkins University. April 4, 2001 edition of JAMA (Vol. 285, 1691-1693)

\section{Crohn's disease}

12. Querida Anderson (2008-06-15). "Osiris Trumpets Its Adult Stem Cell Product". Genetic Engineering \& Biotechnology News (Mary Ann Liebert, Inc.). p. 13. Retrieved 2008-07-06. "(subtitle) Procymal is being developed in many indications, GvHD being the most advanced"

\section{Wound healing}

13. Gurtner GC, Callaghan, MJ and Longaker MT. 2007. Progress and potential for regenerative medicine. Annu. Rev. Med 58:299-31

\section{General}

1. For decreased risk of colon, prostate and lung cancer: "Nutrition to Reduce Cancer Risk". The Stanford Cancer Center (SCC). Retrieved 2008-08-18.

2. For weight loss and cholesterol control: "Apples Keep Your Family Healthy". Washington State Apple Advertising Commission. Retrieved 22 January 2008.

3. Rajeev Sharma. (2005). Improve your health with Apple, Guava,Mango. Diamond Pocket Books (P) Ltd.. pp. 22. ISBN 8128809245.

4. For prevention of dementia: Chan A, Graves V, Shea TB (2006). "Apple juice concentrate maintains acetylcholine levels following dietary compromise". Journal of Alzheimer's Disease 9 (3): 287-291. PMID 16914839.

5. Reference list is found on image page in Commons: Commons:File:Effects of sleep deprivation.svg\#References

6. American Society of Health-System Pharmacists (2009-0323). "Oxycodone". U.S. National Library of Medicine, MedlinePlus. Retrieved 2009-03-27.

7. MedlinePlus (The American Society of Health-System Pharmacists) Drug Information: Hydrocodone. Last Revised - 10/01/2008. Retrieved on $02 / 21 / 2009$

8. Office of National Drug Control Policy (ONDCP): Heroin Facts \& Figures Retrieved on 11 February, 2009

9. "MedlinePlus Drug Information: Tramadol". Retrieved 2009-02-07, Last Revised - 07/01/2007, Last Reviewed - 09/01/2008.

10. MedicineNet > infectious mononucleosis article Retrieved on 7 Mars, 2009

11. WebMD > Infectious Mononucleosis Last Updated: September 19, 2007. Retrieved on 7 Mars, 2009 
12. (History section of) eMedicine Specialties > Infectious Diseases > Infectious Mononucleosis. Author: Burke A Cunha, MD, Professor of Medicine

13. Possible Risks of Blood Product Transfusions from American Cance Society. Last Medical Review: 03/08/2008. Last Revised: 01/13/2009

14. 7 ADVERSE REACTIONS TO TRANSFUSION Pathology Department at University of Michigan. Version July 2004, Revised 11/5/08

15. Fisher, Bruce; Harvey, Richard P.; Champe, Pamela C.. Lippincott's Illustrated Reviews: Microbiology (Lippincott's Illustrated Reviews Series). Hagerstwon, MD: Lippincott Williams \& Wilkins. pp. Chapter 33, pages 367-392. ISBN 0-7817-8215-5.

16. LEF.org > Bacterial Infections Updated: 01/19/2006. Retrieved on April 11, 2009

17. Mainly Chapter 33 (Disease summaries), pages 367-392 in:Fisher Bruce; Harvey, Richard P.; Champe, Pamela C.. Lippincott's Illustrated Reviews: Microbiology (Lippincott's Illustrated Reviews Series). Hagerstwon, MD: Lippincott Williams \& Wilkins. pp. pages 367-392. ISBN 0-7817-8215-5.

18. For common cold: National Institute of Allergy and Infectious Diseases (NIAID) > Common Cold. Last Updated December 10, 2007. Retrieved on 4 April, 2009

19. eMedicineHealth > anemia article Author: Saimak T. Nabili, MD, MPH. Editor: Melissa Conrad Stöppler, MD. Last Editorial Review: 12/9/2008. Retrieved on 4 April, 2009

20. Answers.com Medical Encyclopedia: Metabolic Acidosis: Causes and symptoms By Altha Roberts Edgren. Retrieved on April 13, 2009

21. Symptoms mentioned in both metabolic and respiratory acidosis from the following two references: - Wrongdiagnosis.com > Symptoms of Metabolic Acidosis Retrieved on April 13, 2009 - Wrongdiagnosis.com > Symptoms of Respiratory acidosis Retrieved on April 13, 2009

22. Centers for Disease Control and Prevention > Influenza Symptoms Page last updated November 16, 2007. Retrieved April 28, 2009

23. WebMD > Malaria symptoms Last Updated: May 16, 2007

24. Mayo Clinic > Insomnia > Complications By Mayo Clinic staff. Retrieved on May, 5, 2009

25. Longo, DL; Fauci, AS; Kasper, DL; Hauser, SL; Jameson, JL; Loscalzo, J (2011). "341: disorders of the thyroid gland". Harrison's principles of internal medicine. (18th ed.). New York: McGraw-Hill. ISBN 00717488gX.
26. Longo, DL; Fauci, AS; Kasper, DL; Hauser, SL; Jameson, JL; Loscalzo, J (2011). "341: disorders of the thyroid gland". Harrison's principles of internal medicine. (18th ed.). New York: McGraw-Hill. ISBN $007174889 \mathrm{X}$.

27. MedicineNet > Systemic Lupus (cont.) Last Editorial Review: $1 / 30 / 2009$

28. Toxicity of Carbon Dioxide Gas Exposure, $\mathrm{CO}_{2}$ Poisoning Symptoms, Carbon Dioxide Exposure Limits, and Links to Toxic Gas Testing Procedures By Daniel Friedman - InspectAPedia

29. Davidson, Clive. 7 February 2003. "Marine Notice: Carbon Dioxide: Health Hazard". Australian Maritime Safety Authority.

30. MedlinePlus > Snake bites From Tintinalli JE, Kelen GD, Stapcynski JS, eds. Emergency Medicine: A Comprehensive Study Guide. 6th ed. New York, NY: McGraw Hill; 2004. Update Date: 2/27/2008. Updated by: Stephen C. Acosta, MD, Department of Emergency Medicine, Portland VA Medical Center, Portland, OR. Review provided by VeriMed Healthcare Network. Also reviewed by David Zieve, MD, MHA, Medical Director, A.D.A.M., Inc. Retrieved on 19 mars, 2009

31. Health-care-clinic.org > Snake Bite First Aid - Snakebite Retrieved on 21 mars, 2009

32. Snake bite image example at MDconsult > Patient Education > Wounds, Cuts and Punctures, First Aid for

33. World Resources Institute: August 2008 Monthly Update: Air Pollution's Causes, Consequences and Solutions Submitted by Matt Kallman on Wed, 2008-08-20 18:22. Retrieved on April 17, 2009

34. waterhealthconnection.org > Overview of Waterborne Disease Trends By Patricia L. Meinhardt, MD, MPH, MA, Author. Retrieved on April 16, 2009

35. Pennsylvania State University > Potential Health Effects of Pesticides. by Eric S. Lorenz. 2007.

36. medIND journals > Oxygen Toxicity By Dharmeshkumar N Patel, Ashish Goel, SB Agarwal, Praveenkumar Garg, Krishna K Lakhani. Journal, Indian Academy of Clinical Medicin. Vol. 4, No. 3. JulySeptember 2003

37. eMedicine Specialties > Metabolic Diseases > Hyperammonemia Author: Karl S Roth, MD. Updated: May 31, 2007

38. Figure 8-6, page 288, chapter 8 in: Mitchell, Richard Sheppard Kumar, Vinay; Abbas, Abul K.; Fausto, Nelson. Robbins Basic Pathology. Philadelphia: Saunders. ISBN 1-4160-2973-7. 8th edition.

39. References and comments are found in image description in Commons. 